\title{
The Genus Phytophthora (Peronosporales) in Argentina
}

\author{
El género Phytophthora (Peronosporales) en Argentina
}

\author{
Hemilse Elena Palmucci ${ }^{1 *}$ (D) and Silvia María Wolcan²
}

1. Cátedra de Fitopatología. Facultad de Agronomía. Universidad de Buenos Aires. Av. San Martin 4453. CP 1417. Buenos Aires, Argentina.

2. CIDEFI - UNLP - CICBA, Facultad de Ciencias Agrarias y Forestales, UNLP, 60 y 119, CP 1900. La Plata, Buenos Aires, Argentina.

*palmucci@agro.uba.ar

Citar este artículo

PALMUCCI, H. E. and S. M. WOLCAN. 2020. The Genus Phytophthora (Peronosporales) in Argentina. Bol. Soc. Argent. Bot. 55: 161-193.

DOI: https://doi. org/10.31055/1851.2372.v55. n2.25537

Recibido: 4 Octubre 2019

Aceptado: 20 Mayo 2020

Publicado: 30 Junio 2020

Editora: María Victoria Vignale

ISSN versión impresa 0373-580X

ISSN versión on-line 1851-2372

\section{SUMmARY}

Background and aims: The genus Phytophthora includes plant pathogens that affect a wide host range and cause severe damage and economic losses. The aim of this study was to achieve a more comprehensive knowledge of Phytophthora in Argentina. To this end, a review was carried out from the first reports in the late nineteenth century until March 2019.

M\&M: Information was taken from printed and on-line primary and secondary sources such as Proceedings of National and International Scientific Meetings, Bulletins from National Institutions and Universities, periodical Journals, books and data bases, and then analyzed and categorized.

Results: The revision allowed updating the status of Phytophthora species recorded in the country, considering their geographical distribution, groups of crops affected, host-pathogen relationships, symptoms and nomenclature changes, as well as presenting a quick and comparative access to different subjects related to these pathogens. The results showed that, to date, 20 Phytophthora spp., one species affinis and one taxon affect 223 host-pathogen relationships in Argentina. The diversity of Phytophthora species in the world suggests that a larger number of species, still not cited, could be present in Argentina.

Conclusions: Researchers specialized in the genus Phytophthora, molecular techniques and phylogenetic studies, may allow progressing in the accurate identification of the species and knowledge of their genetic variability.

\section{KEY WORDS}

Argentina, host range, Oomycetes, Peronosporomycetes, Phytophthora, Pseudofungi, Stramenopila.

\section{RESUMEN}

Introducción: El género Phytophthora incluye patógenos de plantas que afectan un amplio rango de hospedantes, causando severos daños y pérdidas económicas. Con la finalidad de conocer el estado actual de la información disponible sobre este género en Argentina, se llevó a cabo una revisión desde fines del siglo XIX hasta marzo de 2019.

M\&M: Se consultaron fuentes primarias y secundarias de información escrita y electrónica: presentaciones en congresos nacionales e internacionales, publicaciones periódicas nacionales e internacionales, boletines de instituciones y universidades, libros y bases de datos. La información obtenida fue analizada y categorizada.

Resultados: La presente revisión permitió actualizar las especies presentes en el país, considerando su distribución geográfica y por grupos de cultivos, relaciones hospedante-patógeno, sintomatología y los cambios en su nomenclatura. Se presenta un rápido y comparativo acceso a los diferentes tópicos relacionados con estas patologías. Se encontraron citadas 20 Phytophthora spp., 1 especie affinis y 1 taxon que afectan a 223 relaciones hospedante-patógeno. La diversidad de Phytophthora spp. citadas en el mundo sugiere que en el país podría haber una mayor cantidad de especies aún no registradas.

Conclusión: Investigadores especializados en el género Phytophthora, técnicas moleculares y estudios filogenéticos permitirán avanzar en la certera identificación de las especies y el conocimiento de su variabilidad genética.

\section{Palabras clave}

Argentina, Oomycetes, Peronosporomycetes Phytophthora, Pseudofungi, rango de hospedantes, Stramenopila. 


\section{INTRODUCTION}

The genus Phytophthora de Bary includes pathogen species that cause diseases in both natural (grasslands or forests) and agricultural ecosystems worldwide, producing severe damage and economic losses. These species can infect a wide variety of ornamental, forest, oleaginous, vegetable and fruit crops, producing symptoms as root, stem and fruit rots, blights, cankers and wilting (Erwin \& Ribeiro, 1996). Most Phytophthora species, such as $P$. nicotianae Breda de Haan, P. cinnamomi R.D. Rands and $P$. citrophthora (R.E. Sm. \& E.H. Sm.) Leonian, affect a wide host range, while others such as $P$. infestans and P. sojae Kaufm. \& Gerd. are host-specific (Erwin \& Ribeiro, 1996; Agrios, 2005). Due to their high virulence and ability to spread disease rapidly, the species of this genus are some of the most important plant pathogens worldwide (Erwin \& Ribeiro, 1996).

Regarding its taxonomic location, the genus Phytophthora has been subject of successive changes. At first, it was considered to belong to the Kingdom Fungi (Whittaker, 1969), whereas, later, due to the existence of numerous morphological and physiological differences with true fungi, it was relocated in the Kingdom Chromista (Cavalier-Smith, 1986) and in the Kingdom Protoctist (Margulis et al., 1989). In this context, these organisms were denominated "pseudofungi" and included into the Subdivision Pseudofungi, Phylum Heterokonta (Kirk et al., 2011). In 2001, Dick placed them within the new Kingdom Stramenopila. This position was supported by characteristics such as the composition of the cellular wall, which is composed of cellulose and beta glucans instead of chitin as in true fungi (Bartnicki-García, 1969); the presence of heterokont spores with two flagella (Desjardins et al., 1969), which allow the zoospores to move in liquid media; the coenocytic mycelia, and different sensitivity to conventional fungicides (Latijnhouwers et al., 2003) among other differences.

Currently, the two classifications that place pseudofungi in the Kingdom Chromista (Class Oomycetes) and the Kingdom Stramenopila (Class Peronosporomycetes) are accepted, although the tendency is to consider them as belonging to the Kingdom Stramenopila (Lamour, 2013).

Based on its morphological and nutritional characteristics, the genus Phytophthora was located in the order Pythiales, family Pythiaceae, along with Pythium Pringsh and related genera for many years (Dick, 2001). Later, molecular studies allowed proposing a close Phytophthora affiliation with the downy mildews in the order Peronosporales and family Peronosporaceae (Hulvey et al., 2010; Beakes et al., 2014; Thines \& Choi, 2016; Beakes \& Thines, 2017).

Molecular-based phylogenies with up to 15 nuclear and mitochondrial genes have been implemented since 2000 (Cooke et al., 2000; Kroon et al., 2004; Blair et al., 2008; Martin et al., 2014; Yang et al., 2017). These studies have placed Phytophthora species in ten welldefined clades.

Several surveys, reviews and taxonomic studies about the genus Phytophthora, including parasitic and/or saprophytic species obtained from soil or water, have been carried out in different countries, including Argentina (Frezzi, 1950, 1977), China (Ho, 1996), England (Brasier \& Strouts, 1976 cited by Lodhi, 2007), New Zealand (Boesewinkel, 1974 cited by Lodhi, 2007), Taiwan (Ann, 1992; Ho et al., 1995) and the USA (Campbell \& Hendrix, 1967; Hendrix \& Campbell, 1970; Erwin \& Ribeiro, 1996). The results of all these studies have greatly contributed to the knowledge of the biodiversity of the genus in different regions.

The most complete review was that published by Erwin \& Ribeiro (1996) in the USA. This review provided extensive information about Phytophthora spp. and deepened different aspects about their worldwide distribution, morphology, physiology, taxonomic evolution, pathogenesis, disease control, etc. Later, different surveys were conducted in Sindhum, Pakistan (Lodhi, 2007), Hainan Island, China (Zeng et al., 2009), Spain (Moralejo et al., 2009), the United Kingdom (Denton et al., 2008) and Italy (Cacciola et al., 2008). Other studies were carried out in different regions of the USA by Schwingle et al. (2007), Warfield et al. (2008), Yakabe et al. (2009) and Olson \& Benson (2011), in Mexico by Perez Sierra et al. (2012), and in South America only in Brazil by Luz et al. (2001).

The information referred to Phytophthora is scattered in on-line or printed scientific articles published by National Universities, National or International Scientific Journals or Meetings and books. The aim of this study was to collect, analyze, and organize the information about Phytophthora spp. recorded in Argentina and update their taxonomic nomenclature. 


\section{H. E. Palmucci and S. M. Wolcan - The Genus Phytophthora in Argentina}

\section{Materials and Methods}

The revision of the Phytophthora spp. recorded in Argentina here performed covered the period from the late nineteenth century to March 2019, and considered only the records of Phytophthora spp. affecting plants or related to plant diseases. Both printed and electronic primary and secondary sources of information were consulted. Primary sources included a) Proceedings of National and International Scientific Meetings; b) National Journals such as Boletín de la Sociedad Argentina de Botánica, Revista de la Facultad de Agronomía de la Universidad de Buenos Aires (FAUBA), Revista de la Facultad de Agronomía de la Universidad de La Plata (UNLP), Revista Argentina de Agronomía, and Horticultura Argentina, among others; and c) International Journals such as Australasian Plant Disease Notes, Journal of Plant Pathology, New Disease Reports, Plant Disease, Phytopathology, Plant Pathology, Tropical Plant Pathology, and Revista Fitopatología de la Asociación Latinoamericana de Fitopatología (ALF), among others. Secondary sources included a) books (Marchionatto, 1948, 1950; Fernández Valiela, 1978, 1979; Erwin \& Ribeiro, 1996; b) databases: AGRIS (International Information System for the Agricultural Science \& Technology) 1991-2001 (http://agris.fao.org/); CABPEST CD 1973-1988; 1989-1999; 2000-2002; CABPEST or (CAB International on SilverPlatter, Search and Retrieval Software) 1990-2013; EBSCO Host Research Databases, 1975-2019 (http://search.ebscohost.com); CAB ABSTRACT, 1990-2013 (www.cabi.org/publishing-products/cababstracts); ScienceDirect (http://www.sciencedirect. com); SCOPUS, 1975-2019 (www.scopus.com); Biblioteca Electrónica de Ciencia y Tecnología (www.biblioteca.mincyt.gob.ar) and c) electronic publications: Atlas Fitopatológico de Argentina (Nome, et al. 2019).

The botanical nomenclature of the hosts was based on the International Plant Name Index (www. ipni.org). For the nomenclature of pseudofungi, different databases were consulted: Farr, D.F \& Rossman, A.Y. Fungal Databases; U.S. National Fungus Collections; ARS, USDA, (https://nt.arsgrin.gov/fungaldatabases); Phytophthora Database (www.phytophthoradb.org/species.php) and Index Fungorum (www.indexfungorum.org/Names/ Names.asp).

\section{Results}

The information obtained as a result of the revision was analyzed and categorized and is presented in three tables and one figure.

The species of Phytophthora so far recorded in Argentina, together with their host range, symptoms caused and geographical distribution are shown in Table 1. This Table also includes references of the first report in each province, which in turn include some other significant data about the pathogens or disease descriptions and references of the first molecular characterization of the species.

According to our search, the first reference of Phytophthora in Argentina was P. infestans on potato, cited by Rieder (1887). The following reference was Girola (1898), who wrote about this pathogen. After that time, Lindquist made new findings and detailed descriptions (Lindquist, 1932, 1935, 1938), whereas Frezzi made several reports and two compilations of Phytophthora in Argentina (Frezzi, 1950, 1977). The first compilation (Frezzi, 1950) included an exhaustive morphological characterization of the 11 species known until that time, with their host range, location, and detailed drawings of their morphology, and served as later reference for foreign papers. The second compilation (Frezzi, 1977) included the new report of $P$. cryptogea (Frezzi, 1957) and a wider range of host-pathogen relations and their locations.

Most of the taxonomic identification of Phytophthora spp. has been based on their morphological features and colony patterns on different culture media. Some species such $P$. aff. boehmeriae, $P$. citricola complex, $P$ medicaginis, $P$. megasperma and $P$. syringae were reported only $50-70$ years ago on a few hosts and were not cited again (Table 1). Later, in the 2000s, molecular diagnostic methods to identify Phytophthora spp. began to be applied. This allowed making taxonomic identifications with greater certainty. The first ITS sequence identification was in P. austrocedri (Greslebin et al., 2007). Then, molecular techniques allowed identifying $P$. sojae (Gally et al., 2007), P. palmivora (Lucero et al., 2007), P. cinnamomi (Palmucci et al., 2008), P. nicotianae on different hosts (Lucero et al., 2006; Grijalba et al., 2008; Vetraino et al., 2009; Palmucci et al., 2011a, b, c; 2012, 2013, Palmucci, 2015), P. lacustris (ex P. taxon salixsoil) (Dobra et al., 


\section{Table 1. Phytophthora species cited in Argentina}

${ }^{1}$ Include the year of the first report of each host-pathogen relationship in different provinces and any other remarkable citations as * Molecular analysis. Abbreviations= FF (Ficha Fitopatológica in Spanish), RF (Registro Fitopatológico in Spanish). Both are Phytopathologycal Record Cards. For recently identified species, i.e. P. taxon kelmania, P. lacustris, P. multivora, P. inundata, P. rosacearum and P. termophila, all publications to date were included.

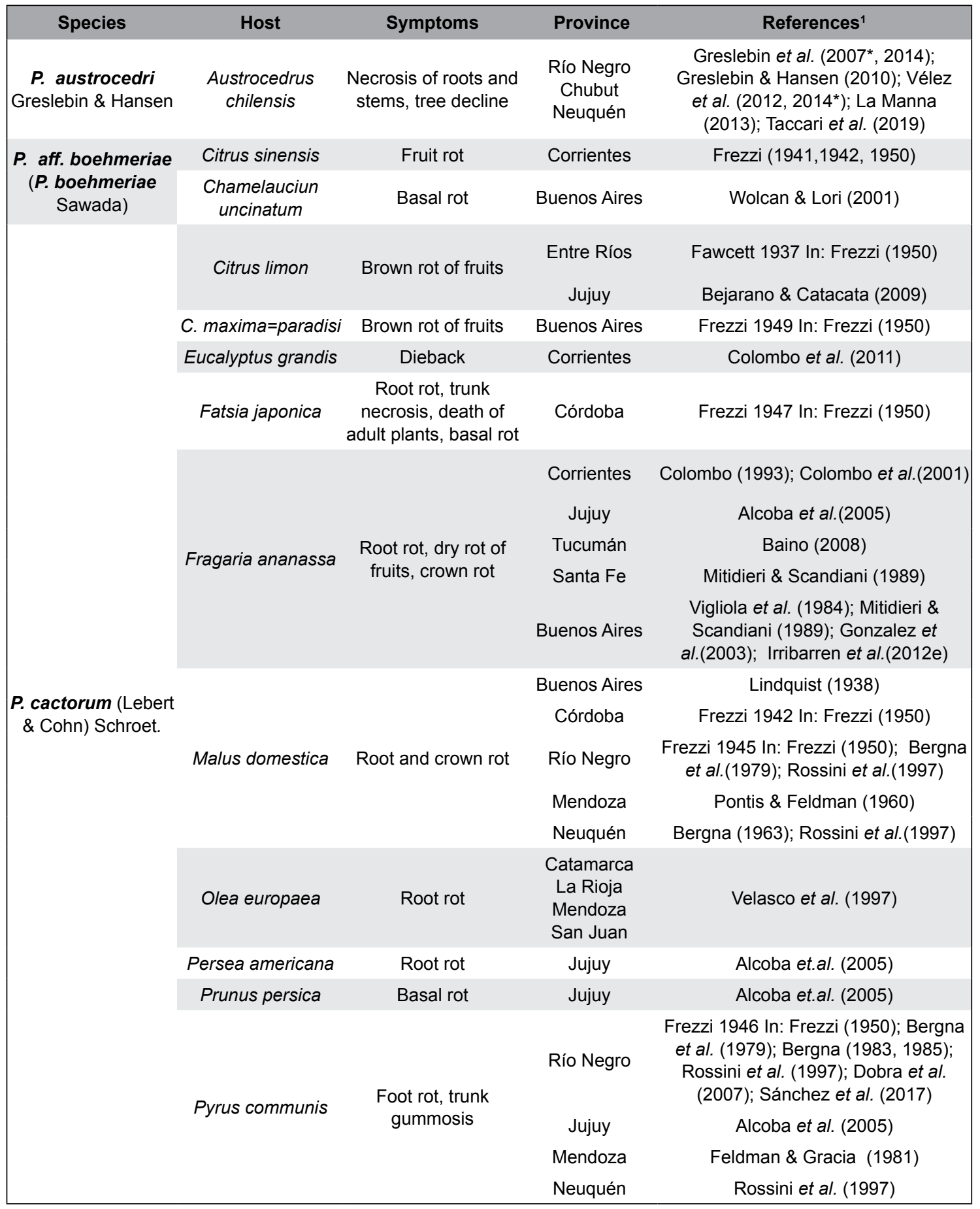




\section{H. E. Palmucci and S. M. Wolcan - The Genus Phytophthora in Argentina}

\begin{tabular}{|c|c|c|c|c|}
\hline Species & Host & Symptoms & Province & References $^{1}$ \\
\hline \multirow{28}{*}{$\begin{array}{l}\text { P. capsici } \\
\text { Leonian }\end{array}$} & Asparagus officinalis & & Mendoza & Velasco \& Camargo (1994) \\
\hline & \multirow{18}{*}{ Capsicum annuum } & \multirow[t]{18}{*}{$\begin{array}{l}\text { Damping-off, root } \\
\text { and crown rot, } \\
\text { fruit rot, blight }\end{array}$} & Buenos Aires & 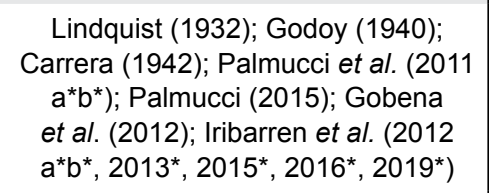 \\
\hline & & & Córdoba & $\begin{array}{l}\text { Carrera (1941a) FF; Frezzi } \\
1942 \text { In: Frezzi (1950) }\end{array}$ \\
\hline & & & Chaco & Bonacic Krecic \& Campagnat (1982) \\
\hline & & & Entre Ríos & Hauman Merck \& Parodi (1921) \\
\hline & & & Tucumán & Traversi (1948) FF \\
\hline & & & Jujuy & Godoy (1940); Alcoba et al. (2005) \\
\hline & & & Corrientes & $\begin{array}{l}\text { Colombo (1988); Mazzanti } \\
\text { de Castañon (1972) }\end{array}$ \\
\hline & & & Catamarca & Raggi (1945) FF \\
\hline & & & La Rioja & Carrera (1940) FF \\
\hline & & & La Pampa & Vitoria (1941) FF \\
\hline & & & Salta & Godoy (1940) \\
\hline & & & San Luis & Carranza (1945) RF \\
\hline & & & San Juan & Oriolani \& Gatica (1980) \\
\hline & & & Santa Fe & Herzog \& Rista (1989) \\
\hline & & & Formosa & $\begin{array}{l}\text { Mazzanti de Castañon et al. (1994); } \\
\text { Bonacic Krecic \& Campagnat (1982) }\end{array}$ \\
\hline & & & Mendoza & $\begin{array}{l}\text { Godoy (1940); Bergna (1963); Oriolani } \\
\text { \& Gatica (1980); Roig et al. (2009) }\end{array}$ \\
\hline & & & $\begin{array}{l}\text { Río Negro } \\
\text { Neuquén }\end{array}$ & Bergna (1963); Rossini et al. (1992) \\
\hline & & & Neuquén & Cipolla (1948a) FF \\
\hline & Coronopus didimus & Yellowing & Buenos Aires & $\begin{array}{l}\text { Iribarren et al. (2017); } \\
\text { Yabar et al. (2017) }\end{array}$ \\
\hline & Cucurbita spp. & $\begin{array}{l}\text { Root and stem } \\
\text { rot, fruit rot. }\end{array}$ & Córdoba & Frezzi 1945 In: Frezzi (1950) \\
\hline & C. pepo & $\begin{array}{l}\text { Root and crown } \\
\text { rot, fruit rot }\end{array}$ & $\begin{array}{l}\text { Río Negro } \\
\text { Neuquén } \\
\text { Buenos Aires }\end{array}$ & $\begin{array}{c}\text { Rossini et al. (1992) } \\
\text { Irribarren et al. (2012a*, 2016) }\end{array}$ \\
\hline & \multirow{4}{*}{$\begin{array}{l}\text { C. maxima var. } \\
\text { zapallito }\end{array}$} & \multirow{4}{*}{$\begin{array}{l}\text { Leaves and fruit } \\
\text { necrosis, root and } \\
\text { crown rot, fruit rot }\end{array}$} & Mendoza & Pontis (1945); Felman \& Pontis (1960) \\
\hline & & & Córdoba & Frezzi 1946 In: Frezzi (1950) \\
\hline & & & $\begin{array}{l}\text { Río Negro } \\
\text { Neuquén }\end{array}$ & Rossini et al. (1992) \\
\hline & & & Buenos Aires & $\begin{array}{l}\text { Mitidieri (1976); Vigliola \& } \\
\text { Calot (1982); Irribarren et al. } \\
\left(2012 a^{*} b^{*}, 2015,2019^{*}\right)\end{array}$ \\
\hline & \multirow[t]{2}{*}{ C. moschata } & \multirow{2}{*}{$\begin{array}{l}\text { Leaves and fruit } \\
\text { necrosis, root and } \\
\text { crown rot, fruit rot }\end{array}$} & $\begin{array}{l}\text { Río Negro } \\
\text { Neuquén }\end{array}$ & Rossini et al. (1992) \\
\hline & & & Buenos Aires & Palmucci et al. $\left(2015^{\star}\right)$ \\
\hline
\end{tabular}




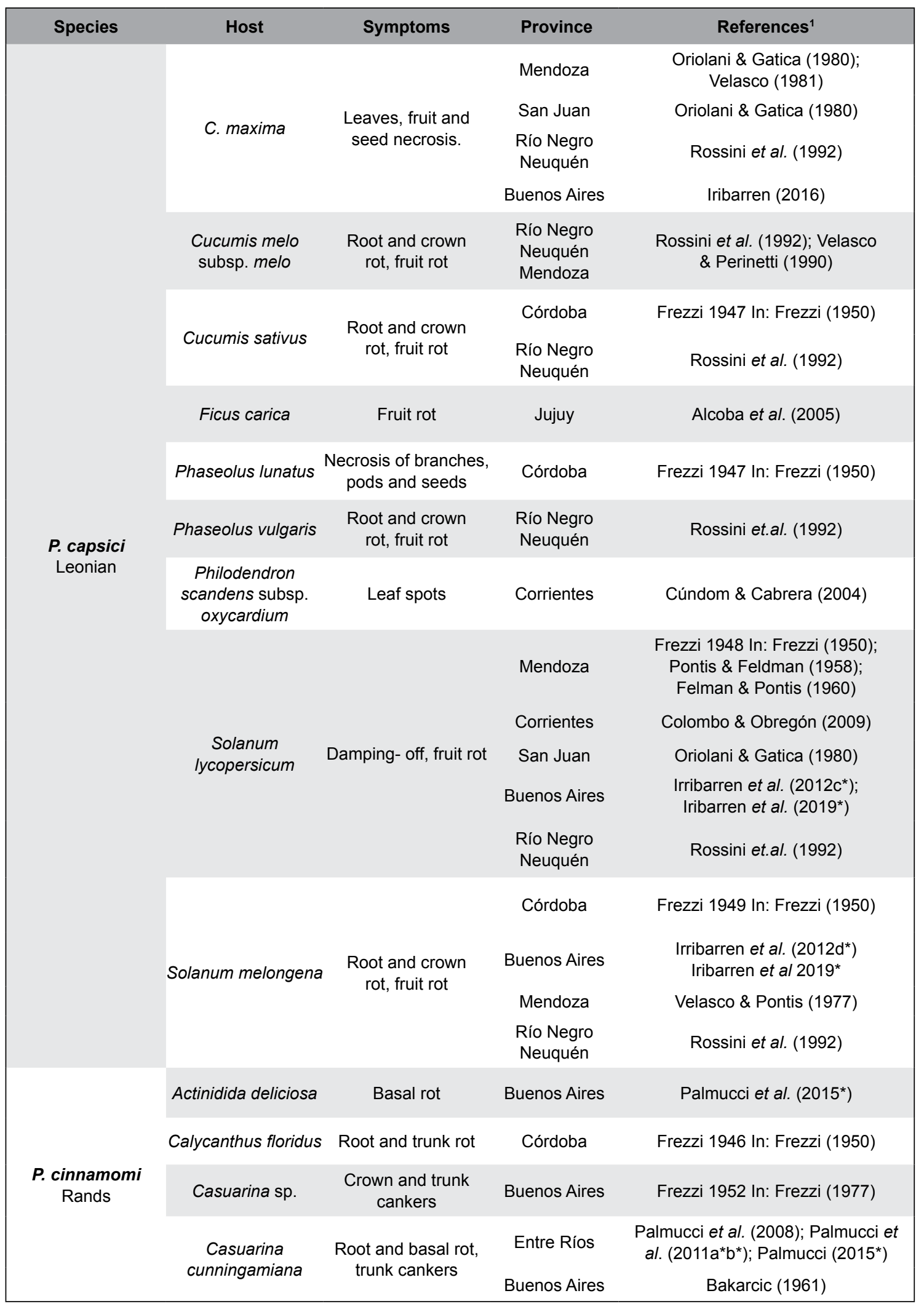


H. E. Palmucci and S. M. Wolcan - The Genus Phytophthora in Argentina

\begin{tabular}{|c|c|c|c|c|}
\hline Species & Host & Symptoms & Province & References $^{1}$ \\
\hline \multirow{26}{*}{$\begin{array}{l}\text { P. cinnamomi } \\
\text { Rands }\end{array}$} & Castanea sativa & Basal rot & Buenos Aires & Marchionatto (1953) \\
\hline & Cupressus sp. & Root rot & Córdoba & Frezzi 1946 In: Frezzi (1950) \\
\hline & Echeveria gibbiflora & Root rot & Córdoba & Frezzi 1949 In: Frezzi (1950) \\
\hline & $\begin{array}{l}\text { Eucalyptus } \\
\text { camaldulensis }\end{array}$ & & & Sarasola \& de Sarasola (1959) \\
\hline & E. rostrata & $\begin{array}{l}\text { Root rot, necrosis of } \\
\text { leaves and twigs }\end{array}$ & Córdoba & Frezzi 1948 In: Frezzi (1950) \\
\hline & Iresine sp. & Necrosis in leaves & Córdoba & Frezzi 1949 In: Frezzi (1950) \\
\hline & Juglans regia & Crown rot & Jujuy & Alcoba et al. (2005) \\
\hline & Ligustrum lucidum & Root and crown rot & Córdoba & Frezzi 1949 In: Frezzi (1950) \\
\hline & \multirow{4}{*}{ Persea americana } & \multirow{4}{*}{ Root and crown rot } & Córdoba & Frezzi 1954 In: Frezzi (1977) \\
\hline & & & Salta & $\begin{array}{c}\text { Frezzi (1952); } 1951 \text { In: Frezzi } \\
\text { (1977); Vazquez de Ramallo (1974) }\end{array}$ \\
\hline & & & Jujuy & $\begin{array}{l}\text { Vazquez de Ramallo (1974); } \\
\text { Flores et al. (2006) }\end{array}$ \\
\hline & & & Tucumán & Frezzi 1972 In: Frezzi (1977) \\
\hline & Phaseolus lunatus & $\begin{array}{l}\text { Necrosis of pods } \\
\text { and seeds }\end{array}$ & Córdoba & Frezzi (1950) \\
\hline & $\begin{array}{l}\text { Pinus radiata- } \\
\text { insigne }\end{array}$ & Root rot & $\begin{array}{c}\text { Córdoba } \\
\text { Buenos Aires }\end{array}$ & $\begin{array}{l}\text { Frezzi } 1946 \text { In: Frezzi (1950) } \\
\text { Bakarcic (1961) }\end{array}$ \\
\hline & Pittosporum tobira & $\begin{array}{l}\text { Necrosis of leaves } \\
\text { and twigs }\end{array}$ & Córdoba & Frezzi 1948 In: Frezzi (1950) \\
\hline & Platanus orientalis & Cankers of trunk & Buenos Aires & $\begin{array}{l}\text { Frezzi } 1949 \text { In: Frezzi } \\
\text { (1950); Bakarcic (1951) }\end{array}$ \\
\hline & Prunus persica & Root and crown rot & Buenos Aires & $\begin{array}{l}\text { Frezzi } 1952 \text { In: Frezzi } \\
\text { (1977); Bakarcic (1961) }\end{array}$ \\
\hline & Quercus robur & Root and crown rot & Buenos Aires & Bakarcic (1961) \\
\hline & Rhododendron sp. & $\begin{array}{l}\text { Root rot and } \\
\text { necrosis of trunk }\end{array}$ & Buenos Aires & Frezzi 1949 In: Frezzi (1950) \\
\hline & $\begin{array}{l}\text { Rhododendron } \\
\text { indicum }\end{array}$ & $\begin{array}{l}\text { Root rot and } \\
\text { necrosis of trunk }\end{array}$ & Buenos Aires & $\begin{array}{l}\text { Frezzi } 1949 \text { In: Frezzi } \\
\text { (1950); Palmucci et al. }(2011 \\
\left.a^{*} b^{*}\right) ; \text { Palmucci }\left(2015^{*}\right)\end{array}$ \\
\hline & Salix caprea & $\begin{array}{c}\text { Root rot and } \\
\text { necrosis of trunk }\end{array}$ & Córdoba & Frezzi 1947 In: Frezzi (1950) \\
\hline & Schinus molle & $\begin{array}{l}\text { Root rot and necrosis } \\
\text { of leaves and twigs }\end{array}$ & Córdoba & Frezzi 1948 In: Frezzi (1950) \\
\hline & Sedum sp. & $\begin{array}{l}\text { Root rot and necrosis } \\
\text { of leaves and twigs }\end{array}$ & Córdoba & Frezzi 1948 In: Frezzi (1950) \\
\hline & $\begin{array}{l}\text { Solanum } \\
\text { Iycopesicum }\end{array}$ & Fruit rot & Córdoba & Frezzi 1949 In: Frezzi (1950) \\
\hline & $\begin{array}{l}\text { Spiraea } \\
\text { cantoniensis }\end{array}$ & Root rot & Córdoba & Frezzi 1947 In: Frezzi (1950) \\
\hline & Thuja sp. & Root rot & Córdoba & Frezzi 1946 In: Frezzi (1950) \\
\hline
\end{tabular}




\begin{tabular}{|c|c|c|c|c|}
\hline Species & Host & Symptoms & Province & References $^{1}$ \\
\hline $\begin{array}{l}\text { P. cinnamomi } \\
\text { Rands }\end{array}$ & $\begin{array}{l}\text { Vaccinium } \\
\text { corymbosum }\end{array}$ & Root and crown rot & $\begin{array}{l}\text { Salta } \\
\text { Tucumán }\end{array}$ & $\begin{array}{l}\text { Hongn et al. (2003) } \\
\text { Hongn et al. (2003); Palmucci et } \\
\text { al. (2011a*b*); Palmucci }\left(2015^{*}\right)\end{array}$ \\
\hline \multirow{3}{*}{$\begin{array}{c}\text { P. citricola } \\
\text { complex (Syn: } \\
\text { P. cactorum (Leb. \& } \\
\text { Cohn) Schroet. var. } \\
\text { applanata Chest.) }\end{array}$} & $\begin{array}{l}\text { Brachytchiton } \\
\text { populneum }\end{array}$ & Necrosis of the apex & Córdoba & Frezzi 1949 In: Frezzi (1950) \\
\hline & Populus alba & $\begin{array}{l}\text { Necrosis of } \\
\text { basal leaves }\end{array}$ & Córdoba & Frezzi 1951 In: Frezzi (1977) \\
\hline & Schinus molle & $\begin{array}{l}\text { Root rot and necrosis } \\
\text { of stem, leaves and } \\
\text { apex of potted plants }\end{array}$ & Córdoba & Frezzi 1947 In: Frezzi (1950) \\
\hline \multirow{15}{*}{$\begin{array}{l}\text { P. citrophthora } \\
\text { (R.E. Sm. \& E.H. } \\
\text { Sm.) Leonian }\end{array}$} & Acer negundo & Crown and trunk rot & Córdoba & Frezzi 1946 In: Frezzi (1950) \\
\hline & $\begin{array}{c}\text { Araucaria } \\
\text { angustifolia }\end{array}$ & $\begin{array}{l}\text { Nurseries: necrosis } \\
\text { of the plant apex } \\
\text { and plant death }\end{array}$ & Córdoba & Frezzi 1943 In: Frezzi (1950) \\
\hline & Antirrhinum majus & Root rot & Córdoba & Frezzi 1953 In: Frezzi (1977) \\
\hline & $\begin{array}{l}\text { Bauhinia forficata } \\
\text { (=B.candicans) }\end{array}$ & $\begin{array}{l}\text { Root rot in } \\
\text { young plants }\end{array}$ & Córdoba & Frezzi 1947 In: Frezzi (1950) \\
\hline & Bignonia sp. & Root and stem rot & Córdoba & Frezzi 1956 In: Frezzi (1970) \\
\hline & $\begin{array}{l}\text { Brachychiton } \\
\text { acerifolia }\end{array}$ & $\begin{array}{l}\text { Root rot and death of } \\
\text { plants (two-years-old) }\end{array}$ & Córdoba & Frezzi 1947 In: Frezzi (1950) \\
\hline & B. populneum & $\begin{array}{l}\text { Root rot, necrosis of } \\
\text { stem and death of } \\
\text { plants (two-years-old) }\end{array}$ & Córdoba & Frezzi 1947 In: Frezzi (1950) \\
\hline & Capsicum annuum & $\begin{array}{l}\text { Damping off, root } \\
\text { and basal rot, fruit rot } \\
\text { and death of plants }\end{array}$ & Córdoba & $\begin{array}{l}\text { Feldman } 1976 \text { In: Frezzi (1977); } \\
\text { Felman \& Gracia (1979) }\end{array}$ \\
\hline & & & Salta & Frezzi 1952 In: Frezzi (1977) \\
\hline & C. pubescens & $\begin{array}{l}\text { Root rot, necrosis } \\
\text { of stem and death } \\
\text { of plants. }\end{array}$ & Córdoba & Frezzi 1949 In: Frezzi (1950) \\
\hline & Castanea sativa & Nurseries: root rot & Mendoza & Frezzi 1955 In: Frezzi (1977) \\
\hline & $\begin{array}{l}\text { Catharanthus } \\
\text { roseus }\end{array}$ & $\begin{array}{l}\text { Root rot and necrosis } \\
\text { of the apex }\end{array}$ & Córdoba & Frezzi 1947 In: Frezzi (1950) \\
\hline & Celtis australis & Root and crown rot & Córdoba & Frezzi 1942 In: Frezzi (1950) \\
\hline & Cicer arietinum & Root rot & Córdoba & Frezzi 1946 In: Frezzi (1950) \\
\hline & Citrus aurantifolia & $\begin{array}{l}\text { Gummosis, damping } \\
\text { off, foot rot and } \\
\text { brown rot of fruits }\end{array}$ & Córdoba & Frezzi 1943 In: Frezzi (1950) \\
\hline
\end{tabular}




\section{H. E. Palmucci and S. M. Wolcan - The Genus Phytophthora in Argentina}

\begin{tabular}{|c|c|c|c|c|}
\hline Species & Host & Symptoms & Province & References $^{1}$ \\
\hline \multirow{27}{*}{$\begin{array}{l}\text { P. citrophthora } \\
\text { (R.E. Sm. \& E.H. } \\
\text { Sm.) Leonian }\end{array}$} & Citrus aurantifolia & $\begin{array}{l}\text { Gummosis, damping } \\
\text { off, foot rot and } \\
\text { brown rot of fruits }\end{array}$ & Corrientes & $\begin{array}{l}\text { Frezzi (1942); Frezzi } 1941 \text { In: Frezzi } \\
\text { (1950); Mazanti de Castañón (1972) }\end{array}$ \\
\hline & \multirow{7}{*}{ C. limon } & \multirow{7}{*}{$\begin{array}{l}\text { Damping off, foot } \\
\text { rot, gummosis, and } \\
\text { brown rot of fruits }\end{array}$} & Corrientes & $\begin{array}{l}\text { Frezzi } 1939 \text { In: Frezzi 1950; } \\
\text { Frezzi (1940; Frezzi (1942 }\end{array}$ \\
\hline & & & Córdoba & Frezzi 1950 In: Frezzi (1977) \\
\hline & & & Tucumán & Stein \& Torres Leal (1991) \\
\hline & & & Entre Ríos & Cipolla (1948b) FF \\
\hline & & & & Frezzi (1950) \\
\hline & & & Buenos Aires & $\begin{array}{l}\text { Marchionatto (1948); } \\
\text { Carranza (1954) RF }\end{array}$ \\
\hline & & & Jujuy & Bejarano \& Catacata (2009) \\
\hline & \multirow{3}{*}{ C. limetioides } & \multirow{3}{*}{$\begin{array}{l}\text { Damping-off, crown } \\
\text { rot of fruits }\end{array}$} & Corrientes & $\begin{array}{l}\text { Frezzi (1942); Frezzi } 1941 \text { In: Frezzi } \\
\text { (1950); Mazanti de Castañón (1972) }\end{array}$ \\
\hline & & & Tucumán & Frezzi (1940) \\
\hline & & & Córdoba & Frezzi \& Mácola (1945) \\
\hline & Citrus jambhiri & Damping-off & Corrientes & $\begin{array}{l}\text { Frezzi } 1941 \text { In: Frezzi (1950); } \\
\text { Mazanti de Castañón (1972) }\end{array}$ \\
\hline & \multirow{7}{*}{ C. sinensis } & \multirow{7}{*}{ Damping off, foot rot } & Corrientes & $\begin{array}{l}\text { Frezzi (1938); Frezzi (1940); Frezzi } \\
\text { (1942); Frezzi } 1939 \text { In: Frezzi } \\
\text { (1950); Marchionatto (1948); } \\
\text { Mazanti de Castañón (1972) }\end{array}$ \\
\hline & & & Córdoba & $\begin{array}{l}\text { Frezzi } 1942 \text { In: Frezzi (1950); } \\
\text { Frezzi \& Mácola (1945) }\end{array}$ \\
\hline & & & Entre Ríos & Marchionatto (1948) \\
\hline & & & Buenos Aires & $\begin{array}{l}\text { Marchionatto (1948); Frezzi } \\
\text { (1960 In: Frezzi (1977) }\end{array}$ \\
\hline & & & Tucumán & Frezzi 1967 In: Frezzi (1977) \\
\hline & & & Salta & Frezzi 1944 In: Frezzi (1950) \\
\hline & & & Jujuy & Bejarano \& Catacata (2009) \\
\hline & C. aurantium & $\begin{array}{l}\text { Gummosis of twigs, } \\
\text { Brown rot of fruits }\end{array}$ & Corrientes & $\begin{array}{l}\text { Frezzi } 1939 \text { In: Frezzi (1950); } \\
\text { Frezzi (1940, 1942); Mazanti } \\
\text { de Castañón (1972) }\end{array}$ \\
\hline & C. nobilis & Brown rot of fruits & Corrientes & Frezzi 1941 In: Frezzi (1950) \\
\hline & \multirow{4}{*}{ C. paradisi } & \multirow{4}{*}{ Brown rot of fruits } & Corrientes & $\begin{array}{l}\text { Frezzi } 1940 \text { In: Frezzi (1950); Frezzi } \\
\text { 1942; Mazanti de Castañón (1972) }\end{array}$ \\
\hline & & & Córdoba & Frezzi 1951 In: Frezzi (1977) \\
\hline & & & Buenos Aires & Frezzi 1960 In: Frezzi (1977) \\
\hline & & & Tucumán & Frezzi (1940) \\
\hline & $\begin{array}{l}\text { C. reticulata } \\
\text { var. austera }\end{array}$ & Brown rot of fruits & Corrientes & $\begin{array}{l}\text { Frezzi } 1941 \text { In: Frezzi } \\
\text { (1950); Frezzi (1942) }\end{array}$ \\
\hline & C. reticulata & $\begin{array}{l}\text { Damping-off, brown } \\
\text { rot of fruits }\end{array}$ & Corrientes & $\begin{array}{l}\text { Frezzi } 1940 \text { In: Frezzi (1950); } \\
\text { Marchionatto (1948); Mazanti } \\
\text { de Castañón (1972) }\end{array}$ \\
\hline
\end{tabular}




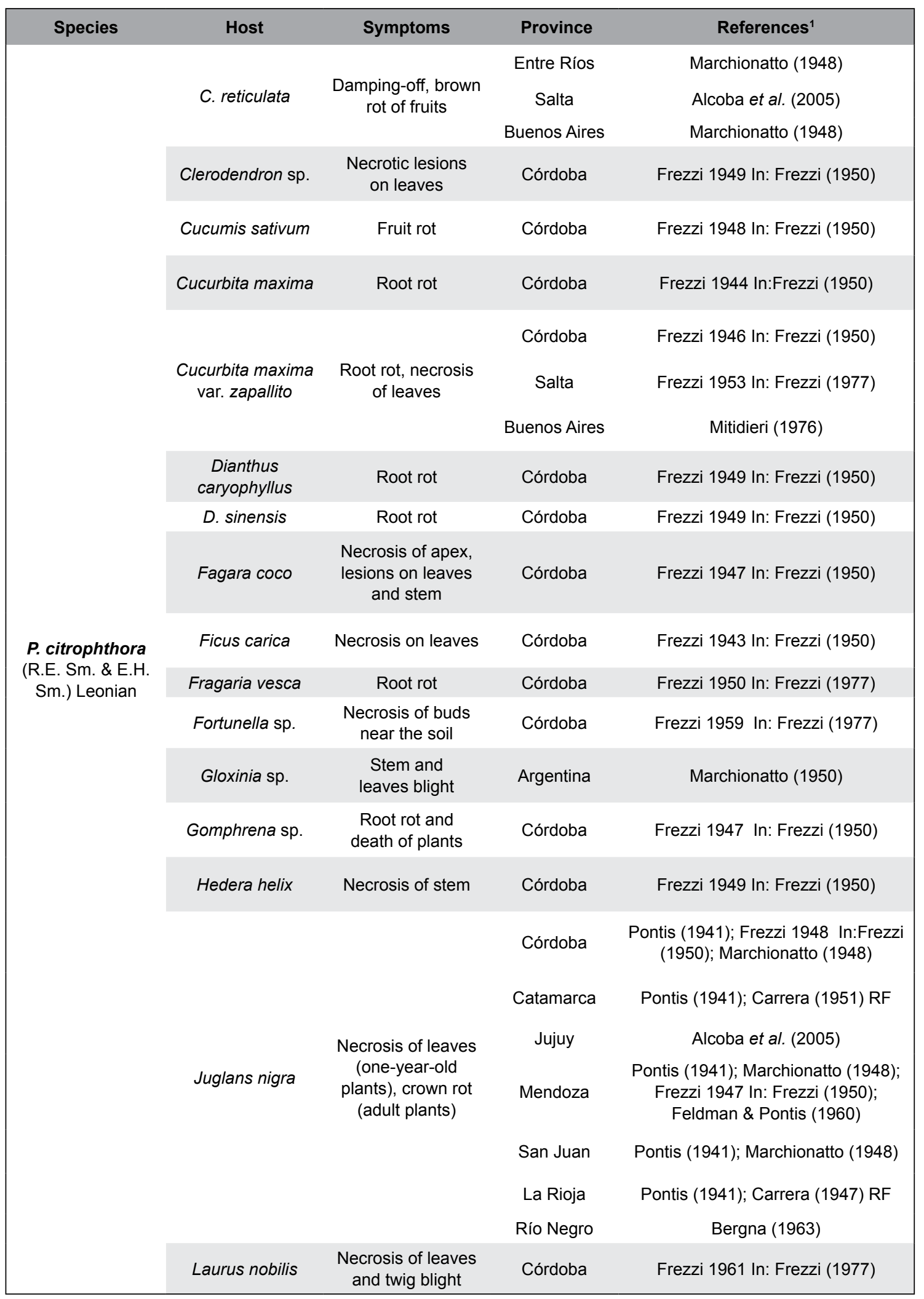


H. E. Palmucci and S. M. Wolcan - The Genus Phytophthora in Argentina

\begin{tabular}{|c|c|c|c|c|}
\hline Species & Host & Symptoms & Province & References $^{1}$ \\
\hline \multirow{16}{*}{$\begin{array}{l}\text { P. citrophthora } \\
\text { (R.E. Sm. \& E.H. } \\
\text { Sm.) Leonian }\end{array}$} & Magnolia grandiflora & $\begin{array}{l}\text { Necrosis of twigs } \\
\text { and plant apex }\end{array}$ & Córdoba & Frezzi 1947 In: Frezzi (1950) \\
\hline & Melia azedarach & $\begin{array}{l}\text { Root rot, necrosis of } \\
\text { the apex, defoliation }\end{array}$ & Córdoba & Frezzi 1948 In: Frezzi (1950) \\
\hline & Nerium oleander & $\begin{array}{l}\text { Necrosis basal } \\
\text { of new stems }\end{array}$ & Córdoba & Frezzi 1956 In: Frezzi (1977) \\
\hline & Olea europea & $\begin{array}{l}\text { Root rot, wilt, } \\
\text { defoliation }\end{array}$ & Mendoza & Lucero et al.(2011b*) \\
\hline & $\begin{array}{l}\text { Petroselinum } \\
\text { crispum }\end{array}$ & $\begin{array}{l}\text { Necrosis of roots } \\
\text { and leaves }\end{array}$ & Córdoba & Frezzi 1958 In: Frezzi (1977) \\
\hline & Pinus halepensis & $\begin{array}{l}\text { Necrosis of the } \\
\text { apex and twigs }\end{array}$ & Córdoba & Frezzi 1943 In: Frezzi (1950) \\
\hline & P. pinea & Necrosis of the apex & Córdoba & Frezzi 1947 In: Frezzi, (1950) \\
\hline & P. radiata & $\begin{array}{l}\text { Necrosis of apex } \\
\text { and twigs }\end{array}$ & Córdoba & Frezzi 1947 In: Frezzi, (1950) \\
\hline & Poncirus trifoliata & Damping-off & Corrientes & $\begin{array}{l}\text { Frezzi (1950); Mazanti de } \\
\text { Castañón (1972) }\end{array}$ \\
\hline & Psidium guayaba & Fruit rot & Córdoba & Frezzi 1953 In: Frezzi (1977) \\
\hline & Populus simonii & Root rot & Mendoza & Feldman \& Pontis (1960) \\
\hline & Punica granatum & Fruit rot & Córdoba & Frezzi 1953 In: Frezzi (1977) \\
\hline & $\begin{array}{c}\text { Robinia } \\
\text { pseudoacacia }\end{array}$ & Root and trunk rot & & Frezzi 1947 In: Frezzi (1950) \\
\hline & Ruta sp. & Root rot & Córdoba & Frezzi 1951 In: Frezzi (1977) \\
\hline & Salvia splendens & $\begin{array}{l}\text { Root rot and necrosis } \\
\text { of branches }\end{array}$ & Córdoba & Frezzi 1947 In: Frezzi (1950) \\
\hline & $\begin{array}{l}\text { Solanum } \\
\text { Iycopersicum }\end{array}$ & Fruit rot & Córdoba & Frezzi 1948 In: Frezzi (1950) \\
\hline \multirow{9}{*}{$\begin{array}{l}\text { P. cryptogea } \\
\text { Pethybr. \& Laff }\end{array}$} & Acer negundo & $\begin{array}{l}\text { Root rot, basal } \\
\text { canker and death } \\
\text { of adult plants }\end{array}$ & Córdoba & Frezzi 1952 In: Frezzi (1977) \\
\hline & Actinidida deliciosa & Root and crown rot & Buenos Aires & $\begin{array}{l}\text { Wolcan \& Ronco (2006); Palmucci } \\
\text { et al. }\left(2011 a^{*} b^{*}\right) ; \text { Palmucci }\left(2015^{\star}\right)\end{array}$ \\
\hline & $\begin{array}{l}\text { Callistephus } \\
\text { chinensis }\end{array}$ & $\begin{array}{l}\text { Root and crown rot, } \\
\text { death of plants }\end{array}$ & $\begin{array}{c}\text { Mendoza } \\
\text { Buenos Aires }\end{array}$ & $\begin{array}{l}\text { Pontis \& Feldman (1959) } \\
\text { Wolcan \& Ronco (2006) }\end{array}$ \\
\hline & Gerbera jamesonii & Basal rot & Buenos Aires & $\begin{array}{l}\text { Wolcan \& Ronco (2006); Palmucci } \\
\text { et al. }\left(2011 a^{*} b^{*}\right) \text {; Palmucci }\left(2015^{*}\right)\end{array}$ \\
\hline & Helianthus annus & Root and crown rot & Buenos Aires & Kiehr et al. (2002); Paoloni et al.(2002) \\
\hline & Ipomea batatas & $\begin{array}{l}\text { Root rot and } \\
\text { death of plants }\end{array}$ & Buenos Aires & Mitidieri 1971 In: Frezzi (1977) \\
\hline & Ocimum basilicum & Basal rot & Buenos Aires & Wolcan \& Ronco (2006) \\
\hline & Prunus avium & $\begin{array}{l}\text { Leaf yellowing } \\
\text { and decline }\end{array}$ & Mendoza & Lucero et al. (2011a*) \\
\hline & Populus simonii & $\begin{array}{c}\text { Root rot and } \\
\text { cankers on trunk }\end{array}$ & Mendoza & Frezzi (1957) \\
\hline
\end{tabular}


Bol. Soc. Argent. Bot. 55 (2) 2020

\begin{tabular}{|c|c|c|c|c|}
\hline Species & Host & Symptoms & Province & References $^{1}$ \\
\hline \multirow{2}{*}{$\begin{array}{l}\text { P. cryptogea } \\
\text { Pethybr. \& Laff }\end{array}$} & Salvia officinalis & Basal rot & Buenos Aires & Wolcan \& Ronco (2006) \\
\hline & $\begin{array}{c}\text { Solanum } \\
\text { lycopersicum }\end{array}$ & Damping off & Buenos Aires & Mitidieri (1995) \\
\hline \multirow{12}{*}{$\begin{array}{l}\text { P. drechsleri } \\
\text { Tucker }\end{array}$} & $\begin{array}{l}\text { Brassica oleracea } \\
\text { var. capitata }\end{array}$ & Root and crown rot & Buenos Aires & Iribarren et al. $\left(2012 \mathrm{~d}^{\star}\right)$ \\
\hline & Capsicum annuum & $\begin{array}{c}\text { Fruit rot and } \\
\text { necrosis of stem }\end{array}$ & Buenos Aires & Iribarren et al. $\left(2019^{*}\right)$ \\
\hline & C. plumosa & $\begin{array}{l}\text { Root rot and necrosis } \\
\text { of stem and branches }\end{array}$ & Córdoba & Frezzi 1947 In: Frezzi (1950) \\
\hline & $\begin{array}{l}\text { Chrysanthemum } \\
\text { cinerariaefolium }\end{array}$ & Root and basal rot & Córdoba & Frezzi 1945 In: Frezzi (1950) \\
\hline & Coleus spp. & $\begin{array}{l}\text { Root rot and } \\
\text { death of plant }\end{array}$ & Córdoba & Frezzi 1949 In: Frezzi (1950) \\
\hline & Pelargonium zonale & Necrosis of roots & Córdoba & Frezzi 1948 In: Frezzi (1950) \\
\hline & Pyrus communis & Fruit rot (in plant) & $\begin{array}{l}\text { Río Negro } \\
\text { Neuquén }\end{array}$ & Sosa et al. $\left(2015^{\star}\right)$ \\
\hline & Salvia officinalis & Root rot & Mendoza & Klingner (1969); Frezzi (1977) \\
\hline & Schinus molle & $\begin{array}{l}\text { Necrosis of leaves } \\
\text { and stem }\end{array}$ & Córdoba & Frezzi 1948 In: Frezzi (1950) \\
\hline & Senecio cruentus & Root and crown rot & Buenos Aires & Carranza (1963) \\
\hline & $\begin{array}{c}\text { Solanum } \\
\text { lycopersicum }\end{array}$ & Rot of green fruits & Córdoba & Frezzi 1949 In: Frezzi (1950) \\
\hline & Solanum melongena & $\begin{array}{c}\text { Necrosis of stems } \\
\text { and fruit rot }\end{array}$ & Buenos Aires & Iribarren et al. $\left(2017^{\star}\right)$ \\
\hline $\begin{array}{c}\text { P. inundata } \\
\text { Brasier, Sánch. } \\
\text { Hern. \& S.A. Kirk }\end{array}$ & Pyrus communis & $\begin{array}{l}\text { Preharvest fruit } \\
\text { rot and root rot }\end{array}$ & Río Negro & Sánchez et al. (2017*; 2019*) \\
\hline \multirow{9}{*}{$\begin{array}{l}P . \text { infestans } \\
\text { (Mont.) de Bary }\end{array}$} & Capsicum annum & $\begin{array}{l}\text { Late blight and } \\
\text { fruit rot }\end{array}$ & Buenos Aires & Prioletta (2006) \\
\hline & Solanum melongena & Fruit rot and wilt & $\begin{array}{l}\text { Northwest } \\
\text { Region }\end{array}$ & Ganem et al. (1992) \\
\hline & \multirow{7}{*}{ S. lycopersicum } & \multirow{7}{*}{$\begin{array}{l}\text { Late blight and } \\
\text { fruit rot. }\end{array}$} & Jujuy & Godoy (1941) FF; Alcoba et al. (2005) \\
\hline & & & Chaco & Bonacic Kresic \& Campagnac, (1982) \\
\hline & & & Santa Fe & Carrera, (1945) RF \\
\hline & & & Buenos Aires & Jauch (1954) FF; Mitidieri (1995) \\
\hline & & & Corrientes & $\begin{array}{l}\text { Carrera (1952) RF; Mazanti } \\
\text { de Castañón (1972) }\end{array}$ \\
\hline & & & Río Negro & Bergna (1963); Colavita et al. (2005) \\
\hline & & & Salta & Frezzi (1950); Alcoba et al. (2005) \\
\hline
\end{tabular}




\begin{tabular}{|c|c|c|c|c|}
\hline Species & Host & Symptoms & Province & References $^{1}$ \\
\hline \multirow{13}{*}{$\begin{array}{l}\text { P. infestans } \\
\text { (Mont.) de Bary }\end{array}$} & \multirow{13}{*}{ S. tuberosum } & \multirow{13}{*}{$\begin{array}{l}\text { Late blight and } \\
\text { downy mildew }\end{array}$} & Buenos Aires & $\begin{array}{c}\text { Rieder (1887); Girola (1898); } \\
\text { Spegazzini (1902); Marchionatto } \\
\text { (1939); Godoy (1943); Frezzi (1950); } \\
\text { Van Damme \& Ridao (1994); Lucca \& } \\
\text { Huarte (2012); Servici et al. (2017*) }\end{array}$ \\
\hline & & & Entre Ríos & Cipolla (1948c) FF \\
\hline & & & Chaco & Calderoni \& Malamud (1966) \\
\hline & & & Santa Fe & $\begin{array}{l}\text { Hauman-Merck (1915); } \\
\text { Carrera }(1941 b) \text { FF }\end{array}$ \\
\hline & & & Córdoba & Frezzi (1950) \\
\hline & & & Misiones & Carrera (1949) FF \\
\hline & & & Jujuy & Alcoba et al. (2005) \\
\hline & & & Río Negro & $\begin{array}{l}\text { Pelayo (1935) FF; Bergna } \\
\text { (1963); Colavita et al. (2005) }\end{array}$ \\
\hline & & & Corrientes & Mazanti de Castañón (1972) \\
\hline & & & San Juan & Oriolani \& Gatica (1980) \\
\hline & & & Mendoza & $\begin{array}{l}\text { Feldman \& Pontis (1960); } \\
\text { Oriolani \& Gatica (1980) }\end{array}$ \\
\hline & & & Salta & $\begin{array}{l}\text { Frezzi } 1950 \text { In: Frezzi (1977); } \\
\text { Alcoba et al. (2005) }\end{array}$ \\
\hline & & & Catamarca & Schechaj (1954) \\
\hline \multirow{3}{*}{$\begin{array}{l}\text { P. taxon kelmania } \\
\text { Abad \& Abad }\end{array}$} & Gerbera jamesonii & Root and basal rot & Buenos Aires & $\begin{array}{l}\left.\text { Palmucci et al. (2011a* } \mathrm{b}^{*}\right) \\
\text { Palmucci }\left(2015^{\star}\right)\end{array}$ \\
\hline & $\begin{array}{l}\text { Gypsophilla } \\
\text { paniculata }\end{array}$ & Root and basal rot & Buenos Aires & Palmucci et al. (2015) \\
\hline & Actinidia deliciosa & Root and basal rot & Buenos Aires & Palmucci et al. $\left(2015^{\star}\right)$ \\
\hline $\begin{array}{l}\text { P. lacustris } \\
\text { Brasier, Cacciola, } \\
\text { Nechwatal, Jung } \\
\text { \& Bakonyi (ex } \boldsymbol{P} \text {. } \\
\text { taxon "Salixsoil") }\end{array}$ & Pyrus communis & $\begin{array}{l}\text { Postharvest fruit } \\
\text { rot, fruit rotin plant }\end{array}$ & $\begin{array}{l}\text { Rio Negro } \\
\text { Neuquén }\end{array}$ & $\begin{array}{l}\text { Dobra et al. }\left(2011^{\star}\right) \\
\text { Sosa et al. }\left(2015^{\star}\right)\end{array}$ \\
\hline \multirow{3}{*}{$\begin{array}{c}P \text {. medicaginis } \\
\text { Hansen \& } \\
\text { Maxwel (ex } P \text {. } \\
\text { megasperma } \\
\text { f.sp. medicaginis } \\
\text { Kuan \& Erwin }\end{array}$} & Medicago sativa & Root rot & Santa Fe & Hijano et al. (1986); Gieco et al. (2007) \\
\hline & Medicago sativa & Root rot & Buenos Aires & Hijano et al. (1986) \\
\hline & Medicago sativa & Root rot & Córdoba & $\begin{array}{l}\text { Hijano et al. (1986); Hijano } \\
1979 \text { In: Hijano (1987) }\end{array}$ \\
\hline \multirow{4}{*}{$\begin{array}{l}\text { P. megasperma } \\
\text { Drechsler }\end{array}$} & Cicer arietinum & Root rot & Córdoba & Frezzi (1950) \\
\hline & Citrus limon & Brown rot of fruits & Buenos Aires & Lindquist 1936 In: Frezzi (1950) \\
\hline & C. paradisi & Brown rot of fruits & Buenos Aires & Frezzi (1950) \\
\hline & C. sinensis & Brown rot of fruits & Corrientes & $\begin{array}{l}\text { Frezzi (1942); Mazanti de } \\
\text { Castañón (1972) }\end{array}$ \\
\hline
\end{tabular}




\begin{tabular}{|c|c|c|c|c|}
\hline Species & Host & Symptoms & Province & References $^{1}$ \\
\hline $\begin{array}{l}\text { P. multivora } \\
\text { Scott \& Jung }\end{array}$ & Rhododendron spp. & $\begin{array}{l}\text { Dark spots from } \\
\text { the leaf apex }\end{array}$ & Buenos Aires & $\begin{array}{l}\text { Grijalba et al. }\left(2012^{*}, 2013^{\star}\right) \\
\text { Grijalba \& Palmucci }(2014)\end{array}$ \\
\hline \multirow{24}{*}{$\begin{array}{c}\text { P. nicotianae } \\
\text { Breda de Haan } \\
\text { (Syn: } \boldsymbol{P} \text {. parasitica) } \\
\text { Dastur }\end{array}$} & Begonia sp. & $\begin{array}{l}\text { Necrotic lesions } \\
\text { on leaves }\end{array}$ & Córdoba & Frezzi 1949 In: Frezzi (1950) \\
\hline & Bignonia sp. & Root and stem rot & Córdoba & Frezzi 1956 In: Frezzi (1977) \\
\hline & $\begin{array}{l}\text { Brachychiton } \\
\text { populneum }\end{array}$ & $\begin{array}{c}\text { Root rot and } \\
\text { necrosis of stem }\end{array}$ & Córdoba & Frezzi 1948 In: Frezzi (1950) \\
\hline & $\begin{array}{l}\text { Callistephus } \\
\text { chinensis }\end{array}$ & Root rot & Córdoba & Frezzi 1947 In: Frezzi (1950) \\
\hline & Carthamus tinctorius & Root rot & Córdoba & Frezzi 1949 In: Frezzi (1950) \\
\hline & Celosia plumosa & $\begin{array}{c}\text { Root rot and } \\
\text { necrosis of stem }\end{array}$ & Córdoba & Frezzi 1947 In: Frezzi (1950) \\
\hline & $\begin{array}{l}\text { Catharanthus } \\
\text { roseus }\end{array}$ & $\begin{array}{l}\text { Apical necrosis } \\
\text { and root rot }\end{array}$ & $\begin{array}{l}\text { Córdoba } \\
\text { Buenos Aires }\end{array}$ & $\begin{array}{l}\text { Frezzi } 1946 \text { In: Frezzi (1950) } \\
\text { Rivera et al. (2000); Palmucci et } \\
\text { al. (2011a*b*); Palmucci (2015) }\end{array}$ \\
\hline & Citrus aurantium & Damping-off & Corrientes & $\begin{array}{l}\text { Frezzi, } 1939 \text { In: Frezzi (1950); } \\
\text { Mazanti de Castañón (1972) }\end{array}$ \\
\hline & & & Córdoba & Frezzi 1942 In: Frezzi (1950) \\
\hline & Citrus aurantifolia & Damping off, foot rot & Corrientes & $\begin{array}{l}\text { Frezzi (1938); Frezzi } 1937 \text { In: Frezzi } \\
\text { (1950); Mazanti de Castañón (1972) }\end{array}$ \\
\hline & & & Buenos Aires & Frezzi 1960 In: Frezzi (1977) \\
\hline & Citrus limettioides & Damping off & Corrientes & Mazanti de Castañón (1972) \\
\hline & \multirow{6}{*}{ Citrus limon } & \multirow{6}{*}{$\begin{array}{l}\text { Foot rot, trunk } \\
\text { gummosis and } \\
\text { brown rot of fruits }\end{array}$} & Corrientes & $\begin{array}{c}\text { Frezzi (1938); Frezzi } 1937 \text { In: Frezzi } \\
\text { (1950); Frezzi (1940); Frezzi (1942); } \\
\text { Mazanti de Castañón (1972) }\end{array}$ \\
\hline & & & $\begin{array}{l}\text { Santiago } \\
\text { del Estero }\end{array}$ & Frezzi 1948 In: Frezzi (1950) \\
\hline & & & Tucumán & $\begin{array}{l}\text { Frezzi (1940); Frezzi } 1939 \text { In: Frezzi } \\
\text { (1950); Stein \& Torres Leal (1991) }\end{array}$ \\
\hline & & & Salta & Frezzi 1944 In: Frezzi (1950) \\
\hline & & & Buenos Aires & $\begin{array}{l}\text { Cipolla (1948d) FF; Frezzi } \\
1960 \text { In: Frezzi (1977) }\end{array}$ \\
\hline & & & Jujuy & Bejarano \& Catacata (2009) \\
\hline & \multirow{3}{*}{ Citrus nobilis } & \multirow{3}{*}{$\begin{array}{l}\text { Foot rot and brown } \\
\text { rot of fruits }\end{array}$} & Corrientes & $\begin{array}{l}\text { Frezzi (1938); Frezzi } 1939 \text { In: } \\
\text { Frezzi (1950); Frezzi (1942) }\end{array}$ \\
\hline & & & Córdoba & $\begin{array}{l}\text { Frezzi } 1942 \text { In: Frezzi (1950); } \\
\text { Frezzi \& Mácola (1945) }\end{array}$ \\
\hline & & & Buenos Aires & Frezzi 1960 In: Frezzi (1977) \\
\hline & Citrus paradisi & $\begin{array}{l}\text { Foot rot and brown } \\
\text { rot of fruits }\end{array}$ & Corrientes & $\begin{array}{l}\text { Frezzi (1938); Frezzi (1942); Frezzi } \\
\text { (1950); Mazanti de Castañón (1972) }\end{array}$ \\
\hline & $\begin{array}{l}\text { Citrus reticulata } \\
\text { var. austera }\end{array}$ & $\begin{array}{l}\text { Foot rot and brown } \\
\text { rot of fruits }\end{array}$ & Corrientes & $\begin{array}{l}\text { Frezzi } 1938 \text { In: Frezzi (1950); } \\
\text { Mazanti de Castañón (1972) }\end{array}$ \\
\hline & Citrus sinensis & $\begin{array}{l}\text { Damping.off, foot rot } \\
\text { and brown rot of fruits }\end{array}$ & Corrientes & $\begin{array}{l}\text { Fawcett (1936); Frezzi } 1937 \text { In: } \\
\text { Frezzi (1950); Frezzi (1942); } \\
\text { Mazanti de Castañón (1972) }\end{array}$ \\
\hline
\end{tabular}




\section{H. E. Palmucci and S. M. Wolcan - The Genus Phytophthora in Argentina}

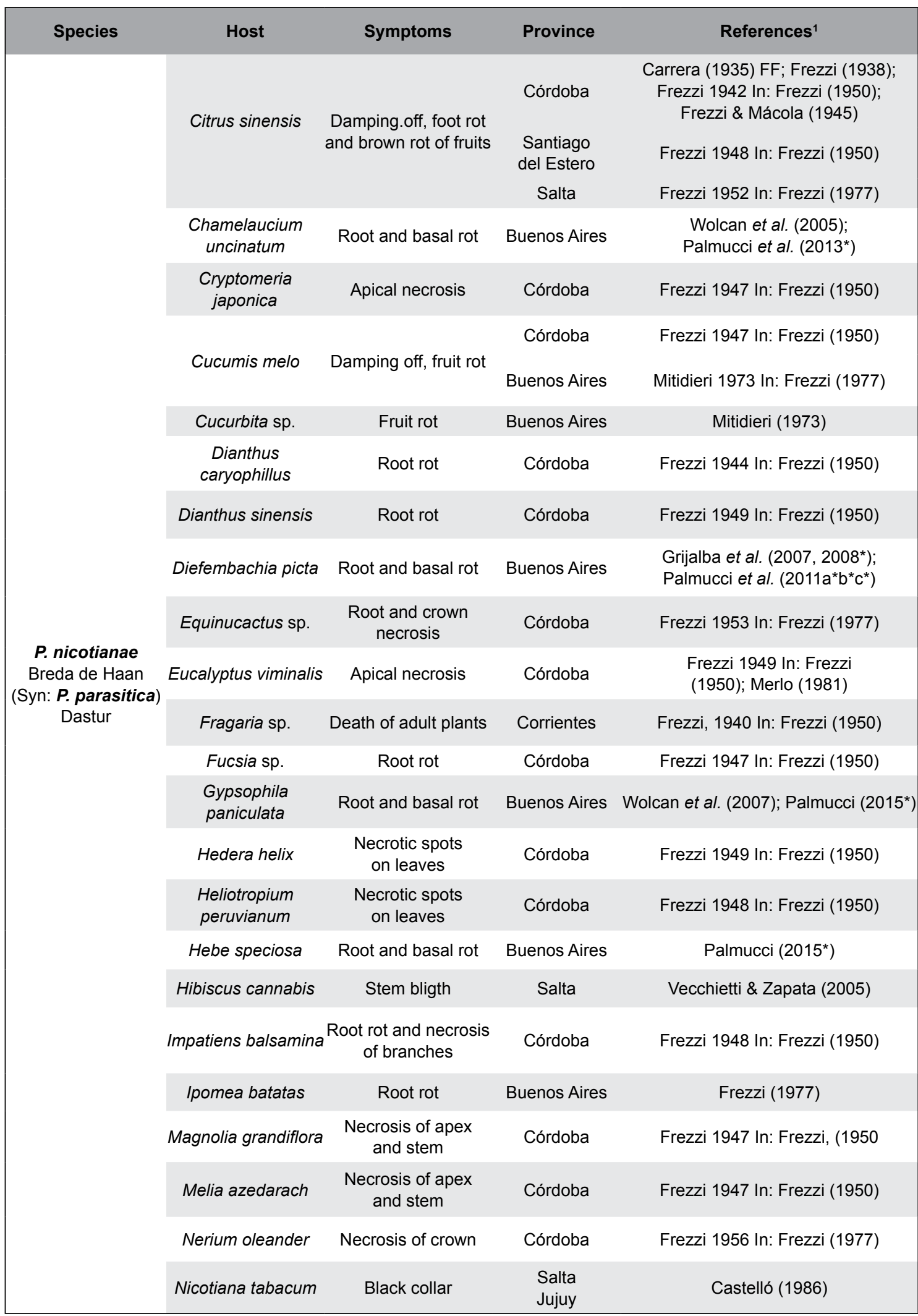




\begin{tabular}{|c|c|c|c|c|}
\hline Species & Host & Symptoms & Province & References $^{1}$ \\
\hline \multirow{17}{*}{$\begin{array}{c}P \text {. nicotianae } \\
\text { Breda de Haan } \\
\text { (Syn: } \boldsymbol{P} \text {. parasitica) } \\
\text { Dastur }\end{array}$} & Olea europea & $\begin{array}{l}\text { Root rot and } \\
\text { twigs wilting }\end{array}$ & Mendoza & Vettraino et al. $\left(2009^{*}\right)$ \\
\hline & Oncidium sp. & $\begin{array}{l}\text { Necrosis of base } \\
\text { of leaves }\end{array}$ & Córdoba & Frezzi 1958 In: Frezzi (1977) \\
\hline & Phaseolus lunatus & $\begin{array}{l}\text { Necrosis of pod } \\
\text { and green seed }\end{array}$ & Córdoba & Frezzi 1947 In: Frezzi (1950) \\
\hline & Phaseolus vulgaris & & Salta & Alcoba et al. (2005) \\
\hline & Pinus halepensis & Root rot & Córdoba & Frezzi 1945 In: Frezzi (1950) \\
\hline & Punica granatum & $\begin{array}{l}\text { Necrotic lesions } \\
\text { of leaves }\end{array}$ & Córdoba & Frezzi 1949 In: Frezzi (1950) \\
\hline & Primula obconica & Root and crown rot & Buenos Aires & Palmucci et al. (2015) \\
\hline & Rheum rhaponticum & Crown rot & Buenos Aires & Lindquist (1935) RF \\
\hline & Ricinus communis & Leaf bligth & Tucumán & Vazquez de Ramallo (1989) \\
\hline & Salvia splendens & $\begin{array}{l}\text { Root rot and necrosis } \\
\text { of branches }\end{array}$ & Córdoba & Frezzi 1947 In: Frezzi (1950) \\
\hline & Schinus molle & $\begin{array}{l}\text { Apical necrosis of } \\
\text { twigs and branches }\end{array}$ & Córdoba & Frezzi 1947 In: Frezzi (1950) \\
\hline & Sesamum indicum & Root rot & Córdoba & Frezzi 1943 In: Frezzi (1950) \\
\hline & $\begin{array}{l}\text { Simmondsia } \\
\text { chinensis }\end{array}$ & $\begin{array}{c}\text { Crown necrosis } \\
\text { and wilt }\end{array}$ & La Rioja & Lucero et al. (2006) \\
\hline & $\begin{array}{c}\text { Solanum } \\
\text { Iycopersicum }\end{array}$ & Fruit rot & $\begin{array}{l}\text { Córdoba } \\
\text { Buenos Aires }\end{array}$ & $\begin{array}{l}\text { Frezzi } 1949 \text { In: Frezzi (1950) } \\
\text { Irribarren et al. }\left(2014^{*}, 2019^{\star}\right)\end{array}$ \\
\hline & Solanum melongena & Fruit rot & $\begin{array}{l}\text { Córdoba } \\
\text { Buenos Aires }\end{array}$ & $\begin{array}{l}\text { Frezzi } 1947 \text { In: Frezzi (1950) } \\
\text { Irribarren et al. }\left(2014^{*}, 2019^{*}\right)\end{array}$ \\
\hline & $\begin{array}{l}\text { Tradescantia } \\
\text { virginiana }\end{array}$ & $\begin{array}{c}\text { Root rot and } \\
\text { necrosis of leaves }\end{array}$ & Córdoba & Frezzi 1947 In: Frezzi (1950) \\
\hline & $\begin{array}{l}\text { Schlumbergera } \\
\text { truncata }\end{array}$ & Root and cladodes rot & Buenos Aires & $\begin{array}{l}\text { Palmucci et al. }\left(2012^{\star}\right) \text {, } \\
\text { Palmucci }\left(2015^{\star}\right)\end{array}$ \\
\hline \multirow{5}{*}{$\begin{array}{l}\text { P. palmivora (E.J. } \\
\text { Butler) E.J. Butler }\end{array}$} & $\begin{array}{l}\text { Brachychiton } \\
\text { populneum }\end{array}$ & Root rot & Córdoba & Frezzi 1946 In: Frezzi (1950) \\
\hline & $\begin{array}{c}\text { Chamaedorea } \\
\text { elegans }\end{array}$ & Leaf spots & Corrientes & Cúndom et al. (2006) \\
\hline & Chamaerodea spp. & Leaf spots & $\begin{array}{l}\text { Chaco } \\
\text { Corrientes }\end{array}$ & Cúndom et al. (2004) \\
\hline & Citrus limon & Brown rot of fruits & Córdoba & Frezzi \& Mácola (1943) \\
\hline & Citrus sinensis & $\begin{array}{l}\text { Foot rot, brown } \\
\text { rot of fruits }\end{array}$ & Córdoba & $\begin{array}{l}\text { Frezzi } 1942 \text { In: Frezzi (1950); } \\
\text { Frezzi \& Mácola (1943) }\end{array}$ \\
\hline
\end{tabular}




\section{H. E. Palmucci and S. M. Wolcan - The Genus Phytophthora in Argentina}

\begin{tabular}{|c|c|c|c|c|}
\hline Species & Host & Symptoms & Province & References $^{1}$ \\
\hline \multirow{5}{*}{$\begin{array}{l}\text { P. palmivora (E.J. } \\
\text { Butler) E.J. Butler }\end{array}$} & Citrus sinensis & $\begin{array}{l}\text { Foot rot, brown } \\
\text { rot of fruits }\end{array}$ & Misiones & $\begin{array}{l}\text { Fawcett } 1937 \text { In: Fawcett } \\
\quad \& \text { Bitancourt (1940) }\end{array}$ \\
\hline & Eucalyptus viminalis & Damping off & Argentina & Sarasola \& de Sarasola (1959) \\
\hline & Ficus carica & Fruit rot & Tucumán & González et al. $(1997,1998)$ \\
\hline & Olea europea & $\begin{array}{l}\text { Root rot, die- } \\
\text { back, wilt }\end{array}$ & $\begin{array}{l}\text { Catamarca } \\
\text { San Juan } \\
\text { La Rioja }\end{array}$ & Prioletta (2006); Lucero et al. $\left(2007^{\star}\right)$ \\
\hline & Phoenix dactylifera & Damping off & Córdoba & Carrera (1954) FF \\
\hline $\begin{array}{l}\text { P. rosacearum } \\
\text { E.M. Hansen \& } \\
\text { W.F. Wilcox }\end{array}$ & Pyrus communis & $\begin{array}{l}\text { Preharvest fruit } \\
\text { rot and root rot }\end{array}$ & Río Negro & Sánchez et al. $\left(2017^{*} ; 2019^{*}\right)$ \\
\hline \multirow{6}{*}{$\begin{array}{c}\text { P. sojae } \\
\text { Kaufm. \& Gerd. }\end{array}$} & \multirow{6}{*}{ Glyicine max } & \multirow{6}{*}{ Root and basal rot } & $\begin{array}{l}\text { Tucumán } \\
\text { Salta }\end{array}$ & $\begin{array}{c}\text { Ploper et al. (1998, 1999); Distéfano } \\
\text { de Vallone et al. (1999) }\end{array}$ \\
\hline & & & Buenos Aires & 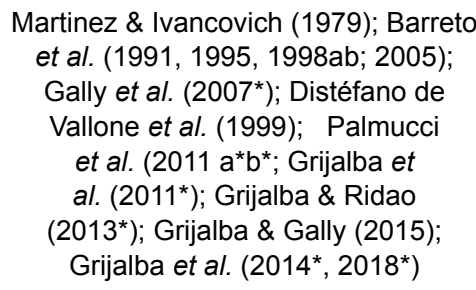 \\
\hline & & & Córdoba & $\begin{array}{l}\text { Barreto et al. (1997, 1998ab; } \\
\text { 2005); Distéfano de Vallone et } \\
\text { al. (1999); Gally et al. (2007*); } \\
\text { Grijalba \& Gally (2015) }\end{array}$ \\
\hline & & & Chaco & Cabrera 2005 In:Cabrera et al. (2009) \\
\hline & & & Santa Fe & $\begin{array}{l}\text { Martinez \& Ivancovich (1979); Barreto } \\
\text { et al.(1998ab, 2005); Gally et al. } \\
\text { (2007*); Distéfano de Vallone et al. } \\
\text { (1999); Grijalba \& Gally (2015) }\end{array}$ \\
\hline & & & Entre Ríos & $\begin{array}{l}\text { Barreto et al. (1997, 1998ab); Gally } \\
\text { et al.(2007*); Grijalba \& Gally (2015) }\end{array}$ \\
\hline \multirow{2}{*}{$\begin{array}{l}\text { P. syringae } \\
\text { Klebahn }\end{array}$} & Citrus limon & Brown rot of fruits & Buenos Aires & Frezzi (1950) \\
\hline & Citrus sinensis & Brown rot of fruits & $\begin{array}{l}\text { Buenos Aires } \\
\text { Entre Ríos }\end{array}$ & $\begin{array}{c}\text { Frezzi (1950) } \\
\text { Pereda (1955) FF }\end{array}$ \\
\hline $\begin{array}{c}\text { P. thermophila } \\
\text { T. Jung, M.J.C. } \\
\text { Stukely \& T. Burgess }\end{array}$ & Pyrus communis & $\begin{array}{l}\text { Preharvest fruit } \\
\text { rot and root rot }\end{array}$ & Río Negro & Sánchez et al. $\left(2017^{*}, 2019^{*}\right)$ \\
\hline
\end{tabular}


2011), P. cryptogea on two hosts (Lucero et al., 2011a; Palmucci et al., 2011a, b; Palmucci, 2015), $P$. citrophthora (Lucero et al., 2011b), P. taxon kelmania (Palmucci et al., 2011a, b; Palmucci, 2015), P. sojae (Grijalba et al., 2011; Palmucci et al., 2011a, b), P. capsici (Palmucci et al., 2011a, b; Palmucci, 2015; Gobena et al., 2012; Iribarren et al., 2012a, b; 2013), P. drechsleri (Iribarren et al., 2012b, e; Sosa et al., 2015; Iribarren et al., 2017), P. multivora (Grijalba et al., 2013; Grijalba \& Palmucci, 2014), and P. inundata, $P$. rosacearum, and P. termophila (Sanchez et al., 2017, 2019).

During the last few years, some studies about the genetic variability of populations of $P$. austrocedri (Velez et al., 2014), P. capsici (Gobena et al.,
2012; Iribarren et al., 2013, 2015, 2016) and $P$. infestans (Lucca \& Huarte, 2012) were carried out. Also others about the virulence and races of Phytophthora sojae were carried out (Grijalba \& Ridao, 2013; Grijalba et al., 2014, 2018; Grijalba \& Gally, 2015).

The species affecting a greater number of hosts are $P$. citrophthora (55), $P$. nicotianae (54) and $P$. cinnamomi (31) (Table 2). On the other hand, other species as $P$. austrocedri (1), $P$. medicaginis (1) and $P$. sojae (1) have specific hosts, and some others, which have been recently identified, as $P$. inundata, $P$. lacustris, $P$. multivora, $P$. rosacearum and $P$. thermophila, have been reported only on a single host to date (Table 2).

Table 2. Groups of crops affected by Phytophthora spp.

\begin{tabular}{|c|c|c|c|c|c|c|c|c|}
\hline \multirow{2}{*}{$\begin{array}{l}\text { Phytophthora } \\
\text { spp. }\end{array}$} & \multirow{2}{*}{ Total } & \multicolumn{7}{|c|}{ Groups Of Crops } \\
\hline & & Vegetables & Ornamentals & Forests & Fruits & Forage & Oleaginous & Palms \\
\hline P. austrocedri & 1 & & & 1 & & & & \\
\hline$P$. aff. bohemeriae & 1 & & & & 1 & & & \\
\hline P. cactorum & 11 & & 1 & 1 & 9 & & & \\
\hline P. capsici & 14 & 12 & 1 & & 1 & & & \\
\hline P. cinnamomi & 31 & 2 & 7 & 17 & 5 & & & \\
\hline P. citricola & 3 & & & 3 & & & & \\
\hline P. citrophthora & 55 & 8 & 12 & 17 & 16 & & 2 & \\
\hline P. cryptogea & 11 & 3 & 2 & 2 & 2 & & 2 & \\
\hline P. drechsleri & 12 & 4 & 5 & 1 & 1 & & 1 & \\
\hline P. infestans & 4 & 4 & & & & & & \\
\hline P. inundata & 1 & & & & 1 & & & \\
\hline$P$. taxon kelmania & 3 & & 2 & & 1 & & & \\
\hline P. lacustris & 1 & & & & 1 & & & \\
\hline P. medicaginis & 1 & & & & & 1 & & \\
\hline P. megasperma & 4 & 1 & & & 3 & & & \\
\hline P. multivora & 1 & & 1 & & & & & \\
\hline P. nicotianae & 54 & 9 & 24 & 6 & 9 & & 6 & \\
\hline P. palmivora & 9 & & & 2 & 4 & & & 3 \\
\hline P. rosacearum & 1 & & & & 1 & & & \\
\hline P. sojae & 1 & & & & & & 1 & \\
\hline P. syringae & 3 & & & 1 & 2 & & & \\
\hline P. termophila & 1 & & & & 1 & & & \\
\hline \# Affected hosts & 223 & 43 & 55 & 51 & 58 & 1 & 12 & 3 \\
\hline
\end{tabular}




\section{H. E. Palmucci and S. M. Wolcan - The Genus Phytophthora in Argentina}

The present inventory shows that there are 20 Phytophthora spp., one species affinis and one taxon reported in Argentina, affecting a total of 223 hosts. Considering the percentage of hostpathogen relations of Phytophthora species, $P$. nicotianae and $P$. citrophthora are the main species with $24 \%$, followed by $P$. cinnamomi with $14 \%$ (Fig. 1).
The distribution of Phytophthora species in the different provinces and regions of Argentina are shown in Table 3. Córdoba and Buenos Aires provinces present the greatest number of species, followed by Tucumán, Río Negro and Corrientes. According to the results, $P$. capsici presents the highest distribution along the country, followed by $P$. cactorum, $P$. infestans, and $P$. citrophthora (Table 3).

Table 3. Geographical distribution of Phytophthora spp. in Argentina. Abbreviations= BA: Buenos Aires; Cat: Catamarca; Cba: Córdoba; Ctes: Corrientes; Cha: Chaco; Chu: Chubut; ER: Entre Ríos; Fsa:

Formosa; Juj: Jujuy; LP: La Pampa; LR: La Rioja; Mza: Mendoza; Mis: Misiones; Neu: Neuquén; RN: Río Negro; Sal: Salta; SF: Santa Fe; SJ: San Juan; SL: San Luis; SC: Santa Cruz; SE: Santiago del Estero; TF: Tierra del Fuego and Islas Malvinas; Tuc: Tucumán.

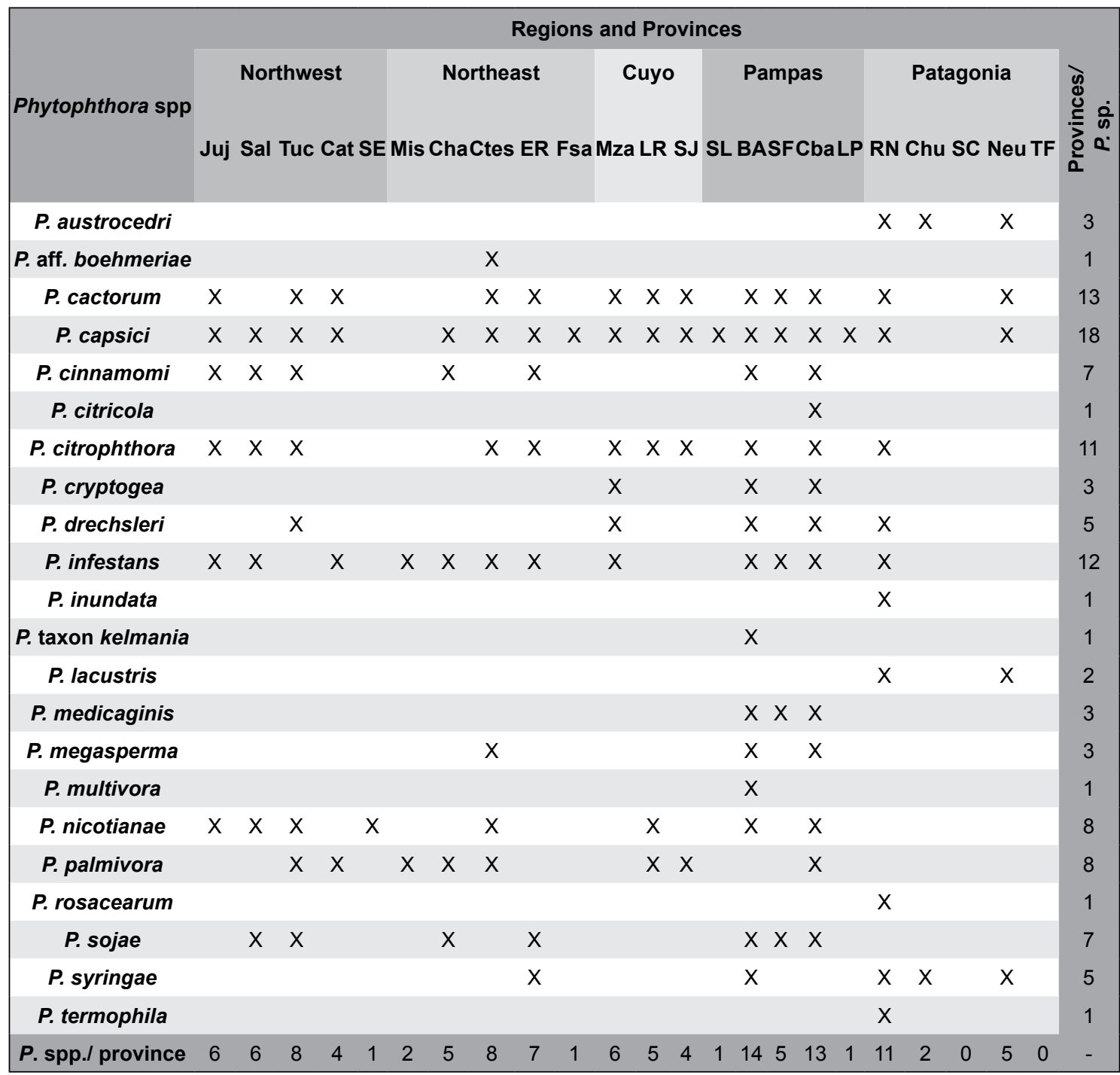




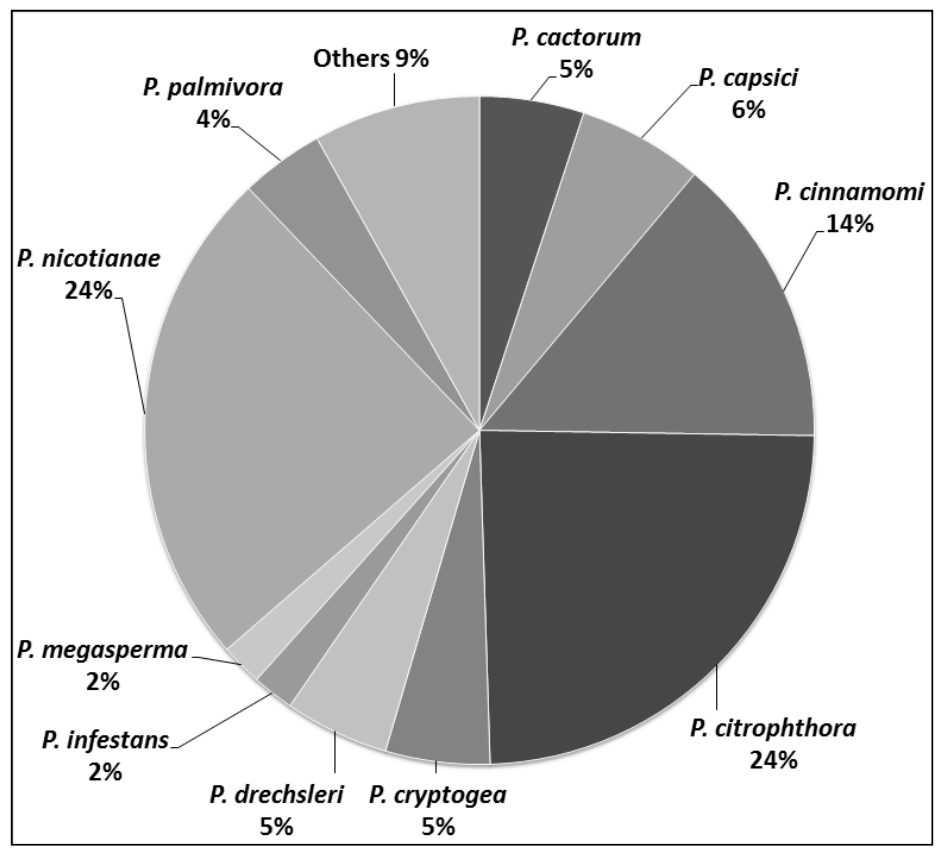

Fig. 1. Host range percentage of each Phytophthora species found in Argentina.

\section{Discussion}

So far, the most complete international review regarding Phytophthora spp. was the one published by Erwin \& Ribeiro in the USA in 1996. These authors provided broad information about Phytophthora spp. worldwide, and presented different types of tables about their worldwide distribution, morphology, physiology, and taxonomic evolution, as well as disease control measures.

The present review allowed the updating of the previous status and inventory of the Phytophthora species present in Argentina (Frezzi, 1950, 1977) as well as of the nomenclature of Phytophthora spp. in relation to that of Frezzi's compilations (Frezzi, 1950, 1977).

There are some issues to be highlighted regarding some species. P. boehmeriae was first mentioned affecting Citrus sinensis in Corrientes province (Frezzi, 1941) (Table 1). Sequences of some of these isolates have been recently used in phylogenetic studies (G. Abad, USDA-APHIS-PPQ, Pers. comm.), in which it was observed that they were not grouped with the isolate sequence Type of $P$. boehmeriae, whereby the isolates obtained by
Frezzi were considered $P$. aff. boehmeriae (Abad, Pers. comm.). In addition, after 1941, P. boehmeriae has not been cited in Argentina again, except by Wolcan \& Lori (2001), who report it causing basal and root rot of Chamelaucium uncinatum. However, more detailed morphobiometric and cultural studies that were made later allowed identifying this oomycete as P. nicotianae (Wolcan et al., 2005), a fact confirmed with the application of molecular analyses and ITS sequencing (Palmucci et al., 2011a, b; Palmucci, 2015). Thus, P. boehmeriae was deleted from the list of Phytophthora spp. in Argentina and the record by Frezzi was replaced by $P$. aff. boehmeriae.

Frezzi also cited P. cactorum var. applanata on three trees (Frezzi, 1950). Waterhouse (1957) later compared the P. citricola original isolates with $P$. cactorum var. applanata and concluded that they were the same species, prioritizing the name $P$. citricola. Currently, P. citricola is recognized as a "species complex" The name $P$. citricola is retained only for isolates whose morphology and sequence information has an exact match with the isolate Type (CBS 221.88) (Lamour, 2013). Since there are no molecular studies of the Argentinian 


\section{H. E. Palmucci and S. M. Wolcan - The Genus Phytophthora in Argentina}

isolates cited in Table 1, they were considered as " $P$. citricola complex".

Another species that was not taken into account in Table 1 was $P$. fragariae. Although there are two reports mentioning this species in the country, neither of them describes the pathogen. In his book about the culture of Fragaria sp., Folquer (1986) named the Phytophthora spp. that caused basal rot on this crop as $P$. fragariae. Later, Alcoba et al. (2005) cited $P$. fragaria again, in Tucumán province, but based only on the symptoms of the plants.

During the first decades of the past century, plant diseases of different crops were recorded by phytopathologists from the Argentine Ministry of Agrarian Affairs along the country. The records were noted in phytopathologycal record cards, which were later compiled by the Institute of Agricultural Technology (INTA). These records about Phytophthora spp. were consulted from the Atlas Fitopatológico de Argentina (Nome et al., 2019). Because of their historical value, some of them were included in Table 1 when it corresponded.

According to the recent online resource "IDphy" (https://idtools.org/id/phytophthora/index.php) there were 182 species described worldwide until May 2018 (Abad et al., 2019). Six new species recently described were not included in IDphy yet. Of the 182 species, 167 can be cultivated.

Taking into account that $P$. boehmeriae was deleted from the list of species, in Argentina, there are currently 20 Phytophthora species, $P$. aff. boehmeriae and $P$. taxon kelmania, cited on 223 host-pathogen relationships. The diversity of Phytophthora species in the world suggests that a higher number of species, still not cited here, could be present in Argentina. Further studies with an extended range of hosts would be necessary to determine in detail the diversity of the Phytophthora population in different cropped areas. It is hoped that molecular and secuentiation techniques will allow a better knowledge of the diversity of Phytophthora species present in Argentina.

\section{Conclusions}

From the $19^{\text {th }}$ century until now, 20 Phytophthora spp., one species affinis and one taxon of Phytophthora have been recorded in Argentina. In recent years, 30\% of them have been identified. Researchers specialized in the genus Phytophthora, molecular techniques and phylogenetic studies, may allow progressing in the accurate identification of the species and knowledge of their genetic variability.

In the context of global climate change, which predisposes the emergence and spread of biotical diseases, this work suggests the need to maximize the study of ecology, species richness, dispersion, pathogenesis, new host-pathogen relations (host switching ability) and the host-Phytophthoraenvironment interactions. This applies both to climate change as a whole as well as to individual factors such as temperature, rainfall, humidity, among others.

\section{AUTHORs' CONTRIBUTION}

The authors shared the tasks of gathering and interpretation of the information, the preparation of tables and figure and the writing of the manuscript.

\section{ACKNOWLEDgeMENTS}

We thank Dr. Gloria Abad for her remarkable comments and suggestions and Ing. Agr. Carlos Carloni for providing some valuable bibliographic references. This paper was written as part of the Ubacyt 033BA Project.

\section{Bibliography}

ABAD, Z.G., BURGESS T., BIENAPFL J.C., REDFORD A.J., COFFEY M., AND KNIGHT L. 2019. IDphy: Molecular and morphological identification of Phytophthora based on the types. USDA APHIS PPQ S\&T Beltsville Lab, USDA APHIS PPQ S\&T ITP, Centre for Phytophthora Science and Management, and World Phytophthora Collection. https://idtools.org/id/phytophthora/index.php, accessed in July 2019.

AGRIOS, G.N. 2005. Plant Pathology. 5a Ed., Academic Press.

ALCOBA, N.J., N. BEJARANO \& J. CATACATA. 2005. Enfermedades de los cultivos de Jujuy y Salta. Diagnosticadas en el Laboratorio de Fitopatología de la Facultad de Ciencias Agrarias de la UNJu. $1^{\mathrm{a}}$ Edición. (Eds.) Editorial de la Universidad Nacional de Jujuy. Ediunju. San Salvador de Jujuy, Argentina. 
ANN, P.J. 1992. Phytophthora diseases of ornamental plants in Araceae in Taiwan. Plant Pathol. Bull. 1:79-89.

BAKARCIC, M. 1951. La cancrosis del plátano. IDIA 42-43: 3-4.

BAKARCIC, M. 1961. Cancrosis de la base del tallo de casuarina. Revista Invest. Agraria 15: 239-248.

BAINO, O.M. 2008. Estado actual de las enfermedades fúngicas en el cultivo de frutilla. 1er Congreso Argentino de Fitopatología. Córdoba, Argentina. Libro de Res.: 85-86.

BARTNICKI-GARCIA, S. 1969. Cell wall differentiation in the Phycomycetes. Phytopathology 59: 10651071.

BARRETO, D., B, STEGMAN DE GURFINKEL \& C. FORTUGNO. 1991. Phytophthora megasperma f. sp. glycinea: Detección y virulencia del patógeno. Actas Primera Reunión Nacional Oleaginosos, Rosario, Argentina: 304-311.

BARRETO, D.E., B. STEGMAN DE GURFINKEL \& C. FORTUGNO. 1995. Races of Phytophthora sojae in Argentina and reaction of soybean cultivars. Plant Disease 79: 599-600. https://doi.org/10.1094/PD-79-0599

BARRETO, D.E., P.E., GRIJALBA \& M.E. GALLY. 1997. Etiología e importancia de las podredumbres de raíz y tallo de la soja, con especial referencia a Phytophthora sojae. II Taller sobre aportes de la Fitopatología a la producción agropecuaria. Finca el Manantial, Tucumán, Argentina. Libro de Res.: 8.

BARRETO, D.E., M.E. GALLY \& P.E. GRIJALBA. 1998a. Razas de Phytophthora sojae en la Región Pampeana (Argentina) en un intervalo de 8 años. Fitopatología 33: 17-18.

BARRETO, D.E., P.E., GRIJALBA, M.E. GALLY, S. DISTÉFANO DE VALLONE \& L.D. PLOPER. 1998b. Prevalencia de Phytophthora sojae en la Región Pampeana Norte de Argentina, caracterización de razas y reacción de cultivares. Fitopatol. Bras. 23: 54-57.

BARRETO, D.E., M.E. GALLY \& P.E. GRIJALBA. 2005. Nuevas razas de Phytophtora sojae en campos de soja en Argentina. XIII Congreso Latinoamericano de Fitopatología. III Taller de la Asociación Argentina de Fitopatólogos. Villa Carlos Paz. Córdoba, Argentina. 19-22 de abril. Libro de Res.: 251.

BEAKES, G.W., D. HONDA \& M. THINES. 2014. Systematics of the Straminipila: Labyrinthulomycota, Hyphochytriomycota, and Oomycota. In
McLAUGHLIN D.J. \& J.W. SPATAFORA (eds.). The mycota VII Part A. Systematics and evolution 2nd ed., pp. 39-97. Springer, Berlin/Heidelberg. https://doi.org/10.1007/978-3-642-55318-9_3.

BEAKES, G.W. \& M. THINES. 2017. Handbook of the Protists. In: ARCHIBALD J. et al. (Eds.) Hyphochytriomycota and Oomycota. pp 1-71. Springer. https://doi.org/10.1007/978-3-319-32669-6_26-1

BEJARANO, N \& J. CATACATA. 2009. Enfermedades fúngicas de mayor prevalencia en la zona citrícola de Jujuy, Argentina. XV Congreso Latinoamericano de Fitopatología. XVIII Congreso Chileno de Fitopatología. Santiago, Chile, 16-12 enero. Libro de Res: 333.

BERGNA, D.A. 1963. Enfermedades citadas sobre plantas cultivadas en las Provincias de Rio Negro y Neuquén. IDIA 182: 38-48.

BERGNA, D.A., F.C., MEYER \& J.A. BARRÍA. 1979. Aislamiento de Phytophthora cactorum (Leb. Et Cohn) Schr. de manzanos y perales con síntomas de marchitamiento. IX Jornadas Argentinas de Micología. Resistencia. Chaco, Argentina. 01-04 de agosto. Libro de Res: 243-247.

BERGNA, D.A. 1983. Etiología de la podredumbre del tronco de los perales. V Jornadas Fitosanitarias Argentinas. Rosario. Santa Fe, Argentina. 7-9 de septiembre. Libro de Res.: 28.

BERGNA, D.A. 1985. Etiología de la podredumbre de los perales en el Alto Valle del Río Negro. II Congreso Latinoamericano de Fitopatología, Buenos Aires, Argentina. Tomo I. Micología: 320-327.

BLAIR, J.E., M.D. COFFEY, S.Y. PARK, GEISER, D.M. \& KANG, S. 2008. A multi-locus phylogeny for Phytophthora utilizing markers derived from complete genome sequences. Fungal Genet. Biol. 45: 266-277. https://doi.org/10.1016/j.fgb.2007.10.010

BONACIC KRESIC, M. de \& N.A. CAMPAGNAC. 1982. Contribución al conocimiento de las enfermedades sobre distintos cultivos en el noreste argentino. Boletín, Vol. 7., Miscelania. INTA-EER Sáenz Peña (eds). Pres. Roque Sáenz Peña, Chaco, Argentina.

CABRERA, M.C., S.A. GUTIÉRREZ \& M.A. CÚMDOM. 2009. Tizón por Phytophthora sojae en cultivos de soja de la provincia del Chaco (Argentina). Summa Phytopathol. 35: 75. https://doi.org/10.1590/S0100-54052009000100019

CACCIOLA, S.O., A. PANE, P. MARTINI, G.E. AGOSTEO, F. RAUDINO \& G. MAGNANO di 


\section{H. E. Palmucci and S. M. Wolcan - The Genus Phytophthora in Argentina}

SAN LIO. 2008. Recovery of Phytophthora species from potted ornamentals in commercial nurseries in Italy. J. Plant Pathol. 90 (S2): 185.

CALDERONI, A.V. \& O. MALAMUD. 1966. Enfermedades de la papa. IDIA 219: 29-36.

CAMPBELL, W.A. \& HENDRIX, F.F. 1967. Pythium and Phytophthora species in forest soil in the southeastern Unites States. Plant Dis. Rep. 52: 929932.

CARRANZA, M.R. 1945. Registro Fitopatológico Nro 000305.3 INTA-IMYZA. Castelar. Buenos Aires. Capsicum annuum L. var. annuum, Phytophthora capsici Leonian. en Villa Mercedes, San Luis, Argentina, 12/04/1945 (In: http://rian.inta.gov.ar/ atlas/\#/Inicio, accessed in November 2018).

CARRANZA J.M. 1954. Registro Fitopatológico Nro 000589.4 INTA-IMYZA. Castelar. Buenos Aires. Citrus limon (L.) Burn, Phytophthora citrophthora (R.E. Sm \& Leonian. E.H. Sm.). en Buenos Aires, Argentina, 4/8/1954 (In: http://rian.inta.gov.ar/ atlas/\#/Inicio, accessed in November 2018).

CARRANZA, J.M. 1963. Podredumbre del cuello y raíces de la cineraria (Senecio cruentus). Rev. Fac. Agron., (La Plata) 39: 1-9.

CARRERA, C.J.M. 1932. Registro Fitopatológico Nro 00797. INTA-IMYZA. Castelar. Buenos Aires. Capsicum annuum L. var. annuum, Phytophthora capsici Leonian. en La Plata, Buenos Aires, Argentina, 03/03/1932 (In: http://rian.inta.gov.ar/ atlas/\#/Inicio, accessed in November 2018).

CARRERA, C.J.M. 1935. Ficha Fitopatológica Nro. 000689.2 Ficheros y Archivos del Instituto de Patología Vegetal INTA. Archivada en: INTA IMYZA Castelar, Buenos Aires. Citrus sinensis L. (Osbeck) Phytophthora parasitica Dastur. En Villa Dolores, Córdoba, Argentina. 21/08/1952 (In: http:// rian.inta.gov.ar/atlas/\#/Inicio, accessed in November 2018).

CARRERA, C.J.M. 1940. Ficha Fitopatológica Nro 000302.1. INTA-IMYZA. Castelar. Buenos Aires. Capsicum annuum L. var. annuum, Phytophthora capsici Leonian. en La Rioja, Argentina, 14/02/1940 (In: http://rian.inta.gov.ar/atlas/\#/Inicio, accessed in November 2018).

CARRERA, C.J.M. 1941a. Ficha Fitopatológica Nro 000302.7. INTA-IMYZA. Castelar. Buenos Aires. Capsicum annuum L. var. annuum, Phytophthora capsici Leonian. en Villa Dolores, Córdoba, Argentina. 11/431041 (In: http://rian.inta.gov.ar/ atlas/\#/Inicio, accessed in November 2018).
CARRERA, C.J.M. 1941b. Ficha Fitopatológica Nro. 002289.1. Ficheros y Archivos del Instituto de Patología Vegetal INTA. Archivada en: INTA IMYZA Castelar, Buenos Aires. Solanum tuberosum L. Phytophthora infestans (Mont.) de Bary. en Rosario, Santa Fe, Argentina, 05/06/1941 (In: http:// rian.inta.gov.ar/atlas/\#/Inicio, accessed in November 2018).

CARRERA, C.J.M. 1942. Estudio sobre la fisiología de la Phytophthora capsici Leonian productora del mildiu o tizón del pimiento en la Argentina. Revista Facultad Agronomia y Veterinaria, Universidad de Buenos Aires 10: 156-191.

CARRERA, C.J.M 1945. Registro Fitopatológico Nro 001469.2, INTA-IMYZA. Castelar. Buenos Aires. Solanum lycopersicum L., Phytophthora infestans (Mont.) de Bary. en Rosario, Santa Fe, Argentina, 12/10/1952 (In: http://rian.inta.gov.ar/atlas/\#/Inicio, accessed in November 2018).

CARRERA, C.J.M. 1947. Registro Fitopatológico Nro 001261.1, INTA-IMYZA. Castelar. Buenos Aires. Juglands regia L., Phytophthora citrophthora (R.E. Sm \& E.H. Sm.) Leonian. en Alcuña, La Rioja, Argentina, 1/08/1947 (In: http://rian.inta.gov.ar/ atlas/\#/Inicio, accessed in November 2018).

CARRERA, C.J.M. 1949. Ficha Fitopatológica Nro. 002295.8. Ficheros y Archivos del Instituto de Patología Vegetal INTA. Archivada en: INTA IMYZA Castelar, Buenos Aires. Solanum tuberosum L. Phytophthora infestans (Mont.) de Bary. en Posadas, Misiones, Argentina, 27/10/1949 (In: http://rian.inta.gov.ar/atlas/\#/Inicio, accessed in November 2018).

CARRERA, C.J.M. 1951. Registro Fitopatológico Nro 001261.2, INTA-IMYZA. Castelar. Buenos Aires. Juglands regia L., Phytophthora citrophthora (R.E. Sm \& E.H. Sm.) Leonian. en Capital, Catamarca, Argentina, 19/10/1951 (In: http://rian.inta.gov.ar/ atlas/\#/Inicio, accessed in November 2018).

CARRERA, C.J.M. 1952. Registro Fitopatológico Nro 001469.3, INTA-IMYZA. Castelar. Buenos Aires. Solanum lycopersicum L., Phytophthora infestans (Mont.) de Bary. en Corrientes, Corrientes, Argentina, 28/09/1945 (In: http://rian.inta.gov.ar/ atlas/\#/Inicio, accessed in November 2018).

CARRERA, C.J.M. 1954. Ficha Fitopatológica Nro 002644. Ficheros y Archivos del Instituto de Patología Vegetal INTA. Archivada en INTA IMYZA Castelar, Buenos Aires. Phoenix dactylifera L., Phytophthora palmivora (E.J. Butler) E.J. Butler. 
En Cruz del Eje, Córdoba, Argentina, 4/8/1954 (In: http://rian.inta.gov.ar/atlas/\#/Inicio, accessed in November 2018).

CASTELLÓ, W.J. 1986. Cuello negro del tabaco, Phytophthora parasitica var. nicotianae, su presencia en la República Argentina. VI Jornadas Fitosanitarias Argentinas. Neuquén, Neuquén, 8-11 abril. Libro de Res s/n.

CAVALIER-SMITH, T. 1986. The kingdom Chromista: origin and systematics. In: ROUND, F.E. \& D.J. CHAPMAN, (eds). Progress in Phycological Research (4): 309-347. Bristol: Biopress.

CIPOLLA, G. 1948a. Ficha Fitopatológica Nro. 000305.5. Ficheros y Archivos del Instituto de Patología Vegetal INTA. Archivada en: INTA IMYZA Castelar, Buenos Aires. Capsicum annuum L. Phytophthora capsici Leonian. Taquimilán, Neuquén, Argentina, 10/03/1948 (In: http://rian.inta. gov.ar/atlas/\#/Inicio, accessed in November 2018).

CIPOLLA, G. 1948b. Ficha Fitopatológica Nro 000589.2. INTA-IMYZA. Castelar. Buenos Aires. Citrus limon (L.) Burn, Phytophthora citrophthora (R.E. Sm. \& E.H. Sm.) Leonian. Gualeguaychú, Entre Ríos, Argentina, 23/06/1948 (In: http://rian.inta.gov.ar/ atlas/\#/Inicio, accessed in November 2018).

CIPOLLA, G. 1948c. Ficha Fitopatológica 002295.5. INTA-IMYZA. Castelar. Buenos Aires. Solanum tuberosum L. Phytophthora infestans (Mont.) de Bary. Gualeguaychú, Entre Ríos, Argentina, 16/7/1948 (In: http://rian.inta.gov.ar/atlas/\#/Inicio, accessed in November 2018).

CIPOLLA, G. 1948d. Ficha Fitopatológica Nro. 000595.2. Ficheros y Archivos del Instituto de Patología Vegetal INTA. Archivada en: INTA IMYZA Castelar, Buenos Aires. Citrus limon (L) Burm. Phytophthora parasitica Dastur. en San Pedro, Buenos Aires. 30/09/1948 (In: http://rian.inta. gov.ar/atlas/\#/Inicio, accessed in November 2018).

COOKE, D.E.L., A. DRENTH, J.M. DUNCAN, G. WAGELS \& C.M. BRASIER. 2000. A molecular phylogeny of Phytophthora and related Oomycetes. Fungal Genet. Biol. 30: 17-32.

https://doi.org/10.1006/fgbi.2000.1202

COLAVITA, M.L., P.L. CORTESE, V. EREZUMA, C. GARCÍA SAMPEDRO, G. GAUDIO, M. KIEHR, D. VILLALBA, M. VILLEGAS \& D. ZAPPACOSTA. 2005. Programa de vigilancia fitosanitaria en cultivos hortícolas en la provincia de Río Negro. XIII Congreso Latinoamericano de Fitopatología. III Taller de la Asociación Argentina de Fitopatólogos. Villa Carlos Paz. Córdoba, Argentina, 19-22 de abril. Libro de Res: 518.

COLOMBO, M. del H. 1988. Phytophthora capsici L. agente causal de la podredumbre del cuello y raíz del pimiento bajo cobertura plástica. XI Congreso Argentino de Horticultura. Asociación Argentina de Horticultura (ASAHO), Mendoza, Argentina. 12 -16 de septiembre. Libro de Res: 37.

COLOMBO, M. del H. 1993. Phytophthora cactorum agente causal de la muerte de plantas de frutilla llamado también colapso vascular. XVI Congreso Argentino de Horticultura. Ciudad de Corrientes, Argentina, 20-24 de septiembre. Libro de Res: 104.

COLOMBO, M. del H., M.P. LENSCAK \& A. ISHIKAWA. 2001. Colapso vascular de plantines frescos de frutilla por Phytophthora cactorum. XXIV Congreso Argentino de Horticultura Medio Ambiente y Sustentabilidad. San Salvador de Jujuy. Jujuy, Argentina, 12-15 de septiembre. Libro de Res: 114.

COLOMBO, M. del H. \& V.G. OBREGÓN. 2009. Principales enfermedades registradas en Corrientes en cultivos de tomate y pimiento en invernadero en el último trienio. II Jornadas de Enfermedades y Plagas en Cultivos Bajo Cubierta. La Plata. Buenos Aires 3-5 de junio. CD: 56.

COLOMBO, M. del H., T. LATTAR, N. CARDOZO \& V.G. OBREGÓN. 2011. Muerte de plantas de Eucalyptus grandis por Phytophthora cactorum en cuello y raíces, Corrientes, Argentina. XXII Reunión de Comunicaciones Científicas, Técnicas y de Extensión. Ciudad de Corrientes. Corrientes, Argentina, 03-05 de agosto. Libro de Res: Sanidad Vegetal.

CÚNDOM, M.A. \& M.G. CABRERA. 2004. Primera determinación de Phytophthora capsici, patógeno de filodendro. Agricultura Técnica 64: 42-45. https://doi.org/10.4067/S0365-28072004000400011

CÚNDOM, M.A., M. CABRERA \& P. CEJAS. 2006. Mancha foliar de Chamaedorea elegans en Corrientes, Argentina. Manejo Integrado de Plagas y Agroecología 77: 82-85.

DENTON, G., J. DENTON, I. WAGHORN \& B. HENRICOT. 2008. Phytophthora diversity in UK gardens. J. Plant Pathol. 90 (S2): 186.

DESJARDINS, P.R., G.A. ZENTMYER \& D.A. REYNOLDS. 1969. Electronic microscopic observations of the flagellar hairs of Phytophthora palmivora zoospores. Can. J. Bot. 47: 1077-1079. https://doi.org/10.1139/b69-153 


\section{H. E. Palmucci and S. M. Wolcan - The Genus Phytophthora in Argentina}

DICK, M.W. 2001. Straminipilous Fungi: Systematics of the Peronosporomycetes including accounts of the marine straminipilous protists, the plasmodiophorids and similar organisms. Kluwer Academic Publishers. The Netherlands.

DISTÉFANO DE VALLONE, S., G.L, BOTTA, L.D, PLOPER, P.E, GRIJALBA, M.E., GALLY, D.E. BARRETO \& B.A. PÉREZ. 1999. Incidencia de Phytophthora sojae en cultivos de soja en las Regiones Pampeana Norte y Noroccidental de Argentina. Mercosoja, Rosario, Santa Fe. 21-25 de junio. Mercosoja 99: 21-22.

DOBRA, A.C., M.N. ROSSINI, N. BARNES \& M.C. SOSA. 2007. Manejo integrado de enfermedades de los frutales de pepita. In: Árboles frutales. Ecología, Cultivo y Aprovechamiento. SOZZI, O. (eds). pp. 586-615. Editorial Facultad de Agronomía. UBA. Buenos Aires.

DOBRA, A.C., M.C, SOSA, M.C. LUTZ, G. RODRIGUEZ, A.G. GRESLEBIN \& M.L. VÉLEZ. 2011. Fruit rot caused by Phytophthora sp. in cold stored pears in the Valley of Rio Negro and Neuquén. Acta Hort. 909: 505-510. https://doi.org/10.17660/ActaHortic.2011.909.59

ERWIN, D.C. \& O.K. RIBEIRO. 1996. Phytophthora Diseases Worldwide. APS. Press. St. Paul, Minnesota.

FARR, D.F. \& A.Y. ROSSMAN. Fungal Databases, U.S. National Fungus Collections, ARS, USDA. Retrieved April 17, 2019, from https://nt.ars-grin. gov/fungaldatabases.

FAWCET, G.L. 1936. Algunos organismos de la gomosis y de la podredumbre del pie del género Citrus. Rev. Ind. Agríc. Tucumán 7: 272.

FAWCET, H.S. \& BITANCOURT, A.A. 1940. Ocurrence, pathogenicity and temperature relations of Phytophthora species on citrus in Brazil and others South American countries. Arq. Inst. Biol. 11: 107-118.

FELDMAN, J.M. \& R.E. PONTIS. 1960. Enfermedades parasitarias de las plantas cultivadas, señaladas para la provincia de Mendoza. Revista Argent. Agron. 27: 27-50.

FELDMAN, J.M. \& O. GRACIA. 1979. Phytophthora citrophthora, nuevo agente del marchitamiento del pimiento en Mendoza. III Reunión Nacional de la Sociedad Argentina de Olericultura. Bermejo, Mendoza. 18-20 de septiembre. Libro de Res: 19.

FELDMAN, J.M. \& O. GRACIA. 1981. La podredumbre del tronco del peral causada por Phytophthora cactorum en Mendoza. IV Jornadas Fitosanitarias Argentinas. Ciudad de Córdoba, Argentina, 19-21 de agosto. Libro de Res: 23.

FERNANDEZ VALIELA, M.V. 1978. Introducción a la Fitopatología, 3a ed., Vol. 3: Hongos. Colección Científica INTA, Buenos Aires. Argentina.

FERNANDEZ VALIELA, M.V. 1979. Introducción a la Fitopatología. 3a ed., Vol. 4: Hongos y Mycoplasmas. Colección Científica INTA. Buenos Aires. Argentina.

FOLQUER, F. 1986. Plagas de Origen Vegetal. In: La Frutilla o Fresa. Hemisferio Sur (eds), Buenos Aires, pp. 113-124.

FLORES, C.R., A. del C. RIDAO, B.A. FERNÁNDEZ VERA, M. RIVADENEIRA \& AGUIRRE, C.M. 2006. Variabilidad en aislamientos de Phytophthora cinnamomi Rands provenientes de cultivos de palta del noroeste argentino. XII Jornadas Fitosanitarias Argentinas. Catamarca 28-30 junio. Libro de Res: 213-214.

FREZZI, M.J. 1938. Podredumbre del pie del naranjo (gomosis) en Bella Vista (Corrientes). Rev. Fac. Agron., La Plata 22: 147-154.

FREZZI, M.J. 1940. La Phytophthora citrophthora, causante de la podredumbre del pie del naranjo y la gomosis del tronco del limonero en Corrientes. Revista Argent. Agron. 7: 165-171.

FREZZI, M.J. 1941. Phytophthora boehmeriae, causante de la podredumbre morena de los frutos citricos, en la República Argentina. Revista Argent. Agron. 8: 200205.

FREZZI, M.J. 1942. Podredumbre morena de los frutos cítricos y parásitos que la producen en Corrientes, Argentina. Revista Argent. Agron. 9: 216-220.

FREZZI, M. \& T. MÁCOLA. 1943. Phytophthora palmivora causante de la Podredumbre morena de los frutos cítricos en Córdoba (Argentina). Revista Argent. Agron. 10: 227-230.

FREZZI, M. \& T. MÁCOLA. 1945. La podredumbre del pie de los Citrus en la provincia de Córdoba, Argentina. Importancia, etiología y medios de lucha. Revista Argent. Agron. 12: 203-211.

FREZZI, M.J. 1947. Contribución al estudio del dampingoff o enfermedad de los almácigos en la República Argentina. Instituto de Sanidad Vegetal. Ministerio de Agricultura de la Nación. Año 3. Ciudad de Buenos Aires. 40 pp.

FREZZI, M.J. 1950. Las especies de Phytophthora en la Argentina. Revista Invest. Agric. 4: 47-133.

FREZZI, M.J. 1952. Phytophthora cinnamomi y su relación con la muerte de los paltos en Urundel 
(Salta), Argentina. Revista Argent. Agron. 19: 214219.

FREZZI, M.J. 1957. "Phytophthora cryptogea" causante de la muerte de "Populus simonii", en Mendoza. Revista Argent. Agron. 24: 136-143.

FREZZI, M.J. 1977. Especies del género Pythium y Phytophthora fitopatógenas identificadas en Argentina. Boletín. (eds.) Serie Didáctica 2. 96 pp. Instituto de Ciencias Agronómicas. UNCb.

GALLY, M.E., A.M. RAMOS, D. DOKMETZIAN \& S.E. LOPEZ. 2007. Genetic variability of Phytophthora sojae isolates from Argentina. Mycologia 99: 877-883. https://doi.org/10.1080/15572536.2007.11832519.

GANEM, M.A., O.M. BAINO \& C.J. RAMALLO. 1992. Determinación de hongos que afectan a la berenjena (Solanum melongena L.) en cultivos del NOA. VIII Jornadas Fitosanitarias Argentinas. Paraná. Entre Ríos. 8-11 de septiembre. Libro de Res.: s/n

GIECO, J.G., M.V. MORENO \& D.H. BASIGALUP. 2007. Enfermedades de la alfalfa y abordaje molecular de la selección por resistencia. En: El Cultivo de la Alfalfa en la Argentina. (Eds.) BASIGALUP, D.H. pp. 449-476. Buenos Aires. https://doi.org/10.1111/ppa.12153

GIROLA, C. 1898. Tizón tardío. Circular $N^{\circ} 36$. Ministerio de Agricultura de la Nación. Ciudad de Buenos Aires. 4 pp.

GOBENA, D., J. ROIG, C. GALMARINI, J. HULVEY \& K. LAMOUR. 2012. Genetic diversity of Phytophthora capsici isolates from pepper and pumpkin in Argentina. Mycologia 104: 102-107. https://doi.org/10.3852/11-147

GODOY, E.F. 1940. El mildew o tizón del pimiento producido por la Phytophthora capsici en la República Argentina. Rev. Fac. Agron. (La Plata) 24: 235-280.

GODOY, E.F. 1941. Ficha Fitopatológica Nro 001469.1. INTA-IMYZA. Castelar. Buenos Aires. Solanum lycopersicum L., Phytophthora infestans (Mont.) de Bary. Calilegua, Jujuy, Argentina, 01/09/1941 (En: http://rian.inta.gov.ar/atlas/\#/Inicio, accessed November 2018).

GODOY, E.F. 1943. Epifitiología del tizón de la papa en la zona papera sudeste de la provincia de Buenos Aires, durante el verano 1940-41. Rev. Fac. Agron. (La Plata) 25: 97-139.

GONZÁlEZ, B.A., M.M STECIOW \& A.M. ARAMBARRI. 2003. Presencia de Phytophthora cactorum en lotes de producción comercial de frutillas de la zona norte de la provincia de Buenos Aires. Bol. Soc. Argent. Bot. 38: 264-265.
GONZÁLEZ, V., C.J. RAMALLO, N.E. VÁZQUEZ DE RAMALLO, L.D. PLOPER \& G.J. TORRES LEAL. 1997. Podredumbre del fruto causada por Phytophthora palmivora en cultivos de higuera en Tucumán, Argentina. IX Congreso Latinoamericano de Fitopatologia, Montevideo, Uruguay. Libro de Res.: 170.

GONZÁLEZ, V., C.J. RAMALLO, N.E. VÁZQUEZ DE RAMALLO, L.D. PLOPPER \& G.J. TORRES LEAL. 1998. Podredumbre del fruto de la higuera causado por Phytophthora palmivora en Tucumán, Argentina. Fitopatología 33: 228-231.

GRESLEBIN, A.G., E.M. HANSEN, L. WINTON \& M. RAJCHENBERG. 2005. Phytophthora species from declining Austrocedrus chilensis forests in Patagonia, Argentina. Mycologia 97: 218-228. https://doi.org/10.1080/15572536.2006.11832855.

GRESLEBIN, A.G., E.M. HANSEN \& W. SUTTON. 2007. Phytophthora austrocedrae sp. nov., a new species associated with Austrocedrus chilensis mortality in Patagonia (Argentina). Mycol. Res. 111: 308-316.

https://doi.org/10.1016/j.mycres.2007.01.008.

GRESLEBIN, A.G. \& E.M. HANSEN. 2010. Pathogenicity of Phytophthora austrocedrae on Austrocedrus chilensis and its relation with mal del ciprés in Patagonia. Plant Pathol. 59: 604-612. https://doi.org/10.1111/j.1365-3059.2010.02258.x

GRESLEBIN, A., M. VELEZ \& L. LA MANNA. 2014. Interacción hospedante-patógeno en ecosistemas boscosos: el caso Austrocedrus chilensisPhythopthora austrocedrae en los bosques de la patagonia andina. XIII Congreso Argentino de Micología, XXIII Jornadas Argentinas de Micología. Buenos Aires, Argentina, Libro. Res. 64.

GRIJAlBA, P.E., H.E. PALMUCCI \& E. GUILLIN. 2008. Identificación de Phytophthora nicotianae afectando plantas de Dieffenbachia picta. I Congreso Argentino de Fitopatología 28 -30 de mayo, Córdoba, Argentina. Libro de Res.: 140.

GRIJALBA, P.E., A. del C. RIDAO \& H.E. PALMUCCI. 2011. New race of Phytophthora sojae in Southern Buenos Aires province (Argentina). Phytopathology 101: S64.

GRIJALBA, P.E., H.E. PALMUCCI, E. GUILLIN \& C. HERRERA. 2012. Phytophthora multivora agente causal de manchas foliares en Rhododendron sp. XIV Jornadas Fitosanitarias Argentinas, Potrero de los Funes, San Luis 3-5 de octubre. Libro de Res.: 31 . 


\section{H. E. Palmucci and S. M. Wolcan - The Genus Phytophthora in Argentina}

GRIJALBA，P.E，H.E. PALMUCCI，E. GUILLIN \& C. HERRERA. 2013. Phytophthora multivora causing leaf spot on rhododendrons in Argentina. New Dis. Rep. 27: 20 (En: http://dx.doi.org/10.519 7/j.2044-0588.2013.027.020, accessed November 2018).

GRIJALBA, P.E. \& A. del C. RIDAO. 2013. Presencia y determinación de razas de Phytophthora sojae en el sur de la provincia de Buenos Aires (Argentina). XXII Congreso Peruano y XVII Congreso Latinoamericano de Fitopatología. Lambayeque. Perú. 01-05 de octubre. Libro de Res.: 33.

GRIJALBA, P.E. \& H.E. PALMUCCI. 2014. Potential hosts of Phytophthora multivora. 7th Meeting of IUFRO Working Party 7.02.09 Phytophthora in Forests and Natural Ecosystems. 10-14 de noviembre. Esquel. Chubut, Argentina. Libro de Res.:84.

GRIJALBA, P.E, A. del C. RIDAO \& M.M. STECIOW. 2014. Prevalencia y caracterización de razas de Phytophthora sojae en el sudeste de Buenos Aires. 3er Congreso Argentino de Fitopatología. Tucumán, Argentina, Libro de Res.: 370.

GRIJALBA, P. \& M. GALLY. 2015. Virulence of Phytophthora sojae in the Pampeana Subregion of Argentina from 1998 to 2004. J. Phytopathology 163: 723-730. https://doi.org/10.1111/jph.12369.

GRIJALBA, P., M.C. MARTÍNEZ, A. del C. RIDAO \& M. STECIOW. 2018. Genetic structure of populations of Phytophthora sojae from north and southeast of Buenos Aires province (Argentina). Phytopathology 108: S1.48. https:// doi.org/10.1094/PHYTO-108-10-S1.1

HAUMAN-MERCK, L. 1915. Les parasites végétaux des plantes cultivées en Argentine et dans les regions limitrophes. Anales Mus. Nac. Hist. Nat. Buenos Aires 26: 163-225.

HAUMAN-MERCK, L. \& L.R. PARODI. 1921. Los parásitos vegetales de las plantas cultivadas en la República Argentina. Rev. Fac. Agron. Vet. Univ. Buenos Aires: 227-274.

HENDRIX, F.F.J. \& W.A. CAMPBELL. 1970. Distribution of Phytophthora and Pythium species in soils in the continental United States. Can. J. Bot. 48: 377-384. https://doi.org/10.1139/b70054.

HERZOG, L.J. \& L.M. RISTA. 1989. Enfermedades más frecuentes en cultivos de pimiento y tomate bajo invernaderos cercanos a la ciudad de Santa Fe. Actas Congreso ASAHO, Santa Fe, Argentina.
HIJANO, E.H., D.H. BASIGALUP, O.A. BRUNO, R.J. LEÓN, G. del V. RINALDI \& M. del C. SPADA. 1986. Diagnósticos comparativos de problemas radiculares de alfalfa en tres localidades de la Argentina. Revista Agropecuaria Manfredi Marcos Juárez 2: 5-21.

HIJANO, E.H. 1987. Podredumbre húmeda de la raíz o fitoftora (Phytophthora megasperma f. sp. medicaginis) de la alfalfa en la Argentina. Revista agronómica de Manfredi (Córdoba. Argentina) 3: 13-22.

HO, H.H., P.J. ANN \& H.S. CHANG. 1995. The genus Phytophthora in Taiwan. Institute of Botany, Academia Sinica. Monograph Series 15: 1-81.

HO, H.H. 1996. The genus Phytophthora in mainland China. Mycotaxon 58: 93-118.

HONGN, S.I., O.M. BAINO, T. PAHILÉ, N.V. CANTON \& J.C. RAMALLO. 2003. Hongos fitopatógenos en arándano en Salta y Tucumán. Argentina. XXVI Congreso Argentino de Horticultura, 30-09 al 0310. Paraná, Entre Ríos, Argentina. Libro de Actas: 62.

HULVEY, J., S. TELLE, L. NIGRELLI, K. LAMOUR \& M. THINES. 2010. Salisapiliaceae - a new family of oomycetes from marsh grass litter of southeastern North America. Persoonia 25: 109 116.

https://doi.org/10.3767/003158510X551763

IRIBARREN, M.J., B.A. GONZÁLEZ, C. BORASSI, A. FERRI \& M.M. STECIOW. 2012a. Caracterización morfológica y molecular de aislamientos de Phytophthora capsici obtenidos de cultivos hortícolas del NE de la provincia de Buenos Aires. XIV Jornadas Fitosanitarias Argentinas. Potrero de Los Funes. San Luis, Argentina, 03-05 de octubre. Libro de Res.: 61.

IRIBARREN, M.J., C. BORASSI, E. GUILLIN, A. FERRI, B.A. GONZÁLEZ \& M.M. STECIOW. 2012b. Estructura genética de Phytophthora capsici en el NE de la Provincia de Buenos Aires. XV Congreso Latinoamericano de Genética. XLI Congreso Argentino de Genética. XLV Congreso de la Sociedad de Genética de Chile. II Reunión Regional SAG-Litoral. Rosario. Libro de Res.: 225. IRIBARREN, M.J., B.A. GONZÁLEZ, C. BORASSI, A. FERRI \& M.M. STECIOW. 2012c. Primer reporte de Phytophthora capsici en brotes de berenjena en el Noreste de la provincia de Buenos Aires. XIV Jornadas Fitosanitarias Argentinas. Potrero de Los Funes, San Luis. Libro de Res.: 60. 
IRIBARREN, M.J., M.L. VELEZ, A. GRESLEBIN, B.A. GONZÁLEZ \& M.M. STECIOW. 2012d. First Report of foliar infection of cabbage by Phytopthora drechsleri in Argentina. Plant Dis. 96: 1830. https://doi.org/10.1094/PDIS-04-12-0342-PDN

IRIBARREN, M.J., B.A. GONZÁLEZ \& S. FILIPPINI. 2012e. Distribución de Phytophthora cactorum en el perfil de un suelo labrado. Summa phytopathol. 38: 17-23. https://doi.org/10.1590/S0100-54052012000100003

IRIBARREN, M.J., C. BORASSI, A FERRI, E. GUILLÍN, B.A. GONZÁLEZ \& M.M. STECIOW. 2013. Genetic structure of Phytophthora capsici populations in the northeast of Buenos Aires Province-Argentina. XXII Congreso Peruano y XVII Congreso Latinoamericano de Fitopatología, Lambayeque, Perú. Libro de Res.: 108.

IRIBARREN, M.J., M. YABAR, B.A. GONZÁLEZ \& M.M. STECIOW. 2014. Caracterización sexual de aislamientos de Phytophthora nicotianae de la zona noreste de la Provincia de Buenos Aires. 3er Congreso Argentino de Fitopatología. Tucumán, Argentina, Libro de Res.: 513.

IRIBARREN, M.J., C. PASCUAN, G. SOTO \& N.D.L AYUB. 2015. Genetic analysis of environmental strains of the plant pathogen Phytophthora capsici reveals heterogeneous repertoire of effectors and possible effector evolution via genomic island. FEMS Microbiol. Lett. 362: 22. fnv189. https://doi.org/10.1093/femsle/fnv189.

IRIBARREN, M.J., C. BORASSI, A. FERRI, B. GONZÁLEZ, M. STECIOW \& E. GUILLÍN. 2016. Estructura genética de poblaciones de Phytophthora capsici en el noreste de la provincia de Buenos Aires, Argentina. RIA 42: 102-112. In: http://www. redalyc.org/articulo.oa?id $=86445998018$, accessed November 2018

IRIBARREN, M.J., B.A. GONZÁLEZ \& M.M. STECIOW. 2017. Primer reporte de infección de frutos y tallos de berenjena por Phytophthora drechsleri en Argentina. $4^{\circ}$ Congreso Argentino de Fitopatología. Mendoza, Argentina, Libro de Res.: 246

IRIBARREN, M.J., M. STECIOW, B. GONZÁLEZ \& M. NARDELLI. 2019. Prevalence and aetiology of Phytophthora fruit and stem rot of solanaceous and cucurbitaceous crops in the Pampas region of Argentina. J. Plant 101: 481-489. https://doi.org/10.1007/s42161-018-00221-2
JAUCH, C. 1954. Ficha Fitopatológica Nro. 001469.4. Ficheros y Archivos del Instituto de Patología Vegetal INTA. En: INTA IMYZA Castelar, Buenos Aires. Lycopersicum esculentum Mill. Phytophthora infestans (Mont.) de Bary. En Longchamps., Buenos Aires, Argentina, 07/01/1954 (In: http://rian.inta.gov. ar/atlas/\#/Inicio, accessed November 2018).

KIEHR, M., R. DELHEY \& P.J. PAOLONI. 2002. Podredumbre de raíces y cuello de girasol bajo riego, causada por Phytophthora cryptogea, en la región pampeana sur. XI Jornadas Fitosanitarias Argentinas, Río Cuarto, Córdoba, Argentina, Libro de Res.: 65.

KIRK, P.M., P.F. CANNON, D.W. MINTER \& J.A. STALPERS. 2011. Ainsworth \& Bisby's Dictionary of the Fungi, 10th ed. CAB International, Wallingford. UK.

KLIGNER, A.E. 1969. Salvia officinalis Linn., un nuevo huésped para Phytophthora drechsleri Tucker. Rev. Fac. Cienc. Agrar., Univ. Nac. Cuyo: 15: 95-201.

KROON, L.P.N.M., F.T. BAKKER, G.B.M. van den BOSCH, P.J.M. BONANTS \& W.G. FLIER. 2004. Phylogenetic analysis of Phytophthora species based on mitochondrial and nuclear DNA sequences. Fungal Genet. Biol. 41: 766-782. https://doi.org/10.1016/j.fgb.2004.03.007

LA MANNA, L., A.G. GRESLEBIN \& S.D. MATEUCCI. 2013. Applying cost-distance analysis for forest disease risk mapping: Phytophthora austrocedrae as an example. Eur. J. For. Res. 132: 877-885. https://doi.org/10.1007/s10342-013-0720-3

LAMOUR,K.H.2013.Phytophthora:AGlobalPerpective. (ed.) LAMOUR, K. CABI Plant Protection series \# 2. https://doi.org/10.1079/9781780640938.0000

LATIJNHOUWERS, M., P.J.G.M. de WIT \& F. GOVERS. 2003. Oomycetes and fungi: similar weaponry to attack plants. Trends Microbiol. 11: 462-469.

https://doi.org/10.1016/j.tim.2003.08.002

LIDQUIST, J.C. 1932. Sobre la presencia de Phytophthora capsici en la República Argentina. Physis 11: 170174.

LINDQUIST, J.C. 1935. Registro Fitopatológico Nro. 01126. Ficheros y Archivos del Instituto de Patología Vegetal. INTA. Archivada en: INTA IMYZA Castelar, Buenos Aires, Argentina. Rheum rhaponticum L., Phytophthora parasitica Dastur. en La Plata, Buenos Aires.

LINDQUIST, J.C. 1938. Muerte de manzanos ocasionada por Phytophthora cactorum. Rev. Fac. Agron., (La Plata) 21: 195-199. 


\section{H. E. Palmucci and S. M. Wolcan - The Genus Phytophthora in Argentina}

LODHI, A.M. 2007. Taxonomic studies on Oomycetous fungi from Sindh. Thesis (In: http://prr.hec.gov.pk/ jspui/handle/123456789/5097, accessed November 2018).

LUCCA, F., \& M. HUARTE. 2012. Genotypic variation of Phytophthora infestans populations in Argentina. Thirteenth EuroBlight workshop St. Petersburg (Russia), 9-12 October 2011. In: PPO-Special Report 15: 201-204.

LUCERO, G., A.M. VETTRAINO, P. PIZZUOLO \& A. VANNINI. 2006. First report of Phytophthora nicotianae on jojoba in Argentina. Plant Pathol. 55: 295. https://doi.org/10.1111/j.13653059.2005.01260.x

LUCERO, G., A.M. VETTRAINO, P. PIZZUOLO, C. DI STEFANO \& A. VANNINI. 2007. First report of Phytophthora palmivora on olive trees in Argentina. Plant Pathol. 56: 728-728. https://doi.org/10.1111/j.1365-3059.2007.01588.x.

LUCERO, G., P. PIZZUOLO, J. BOITEUX, M.V. HAPON, M. OJER, S. FRANCESCHINI, A.M. VETTRAINO \& A. VANINI. 2011a. Primer reporte de Phytophthora cryptogea sobre cerezo en Argentina. II Congreso Argentino de Fitopatología. 1-3 Junio, Mar del Plata, Argentina. Libro de Res.: 121.

LUCERO, G., P. PIZZUOLO, M.V. HAPON, S. FRANCESCHINI, A.M. VETTRAINO \& A. VANNINI. 2011b. Primer reporte de Phytophthora citrophthora aislada de olivo en Argentina. $2^{\circ}$ Congreso Argentino de Fitopatología. 1-3 junio, Mar del Plata, Argentina. Libro de Res.: 148.

LUZ, E.D.M.N., A.F. dos SANTOS S, K, MATSUOKA, \& J.L, BEZERRA. 2001. Doenças causadas por Phytophthora no Brasil. Campinas: Livraria e Editora rural.

MARCHIONATTO, J.B. 1939. Notas micológicas. Physis 15: 133-144.

MARCHIONATTO, J.B. 1948. Tratado de Fitopatologia. Eds. Librería del Colegio. Editorial Sudamericana. Buenos Aires. 537 pp.

MARCHIONATTO, J.B. 1950. Enfermedades de las plantas florales. Eds. Editorial Sudamericana. Compañía Impresora Argentina. Buenos Aires.

MARCHIONATTO, J.B. 1953. Phytophthora cinnamomi sobre castaño en la Argentina. Revista Argent. Agron. 20: 4-6.

MARGULIS, L., J.O. CORLISS, M. MELKONIAN \& D.J. CHAPMAN. 1989. Handbook of protoctista. (eds.) JONES \& BARLETT, Boston.
MARTIN, F.N., J.E. BLAIR \& M. COFFEY. 2014. A combined mitochondrial and nuclear multilocus phylogeny of the genus Phytophthora. Fungal Genet. Biol. 66: 19-32.

https://doi.org/10.1016/j.fgb.2014.02.006

MARTINEZ, C. \& A. IVANCOVICH. 1979. Presencia de Phytophthora megasperma var. sojae en la pampa húmeda. Actas VII Reunión Técnica Nacional de soja, Santa Fe, Argentina.

MAZZANTI DE CASTAÑÓN, M.A. 1972. Enfermedades de las plantas registradas en la provincia de Corrientes. IDIA Supl. 28: 7-27.

MAZZANTI DE CASTAÑÓN, M.A., M.A CÚNDOM. \& M.G CABRERA. 1994. Enfermedades en cultivos protegidos de tomate, pimiento y berenjena, en el nordeste argentino. Hortic. Argent. 13: 1-8.

MERLO, P.A. 1981. Phytophthora nicotianae en Eucalyptus viminalis. Enfermedad de las almácigas (damping off). Ministerio de Economía. Subsecretaria de Asuntos Agrarios (Eds.) pp 1-4. La Plata. Buenos Aires.

MITIDIERI, I.Z.M. de. 1973. Enfermedades criptogámicas nuevas o poco difundidas en la Argentina. IDIA 301: 9-12.

MITIDIERI, I.Z.M. de. 1976. Enfermedades del zapallito de tronco (Cucurbita maxima var. zapallito). INTA, EEA San Pedro. (In: http://rian.inta.gov.ar/atlas/\#/ Inicio, accessed in November 2018).

MITIDIERI, I.Z.M. de \& M.M. SCANDIANI. 1989. Nuevos problemas fitopatológicos en el cultivo de la frutilla. VII Jornadas Fitosanitarias Argentinas. Ciudad de Salta, Argentina, 5-8 de junio. Libro de Res.: $\mathrm{s} / \mathrm{n}$.

MITIDIERI, I.Z.M. de. 1995. Principales enfermedades del tomate cultivado bajo invernáculo: manejo integrado. En: Seminario Manejo Integrado de Plagas y Enfermedades en Cultivos Hortícolas Bajo Cubierta. San Pedro. Buenos Aires. 27-28 de junio (In: http://rian.inta.gov.ar/atlas/\#/Inicio, accessed in November 2018).

MORALEJO, E., A. PÉREZ-SIERRA, L.A. ÁLVAREZ, L. BELBAHRI, F. LEFORT \& E. DESCALS. 2009. Multiple alien Phytophthora taxa discovered on diseased ornamental plants in Spain. Plant Pathol. 58: $100-110$. https://doi.org/10.1111/j.1365-3059.2008.01930.x

NOME, S.F., D.M. DOCAMPO \& L.R. CONCI. 2019. Atlas Fitopatológico de Argentina Instituto Nacional de Tecnología Agropecuaria (In: http://rian.inta.gov. ar/atlas/\#/Inicio, accessed 2014-2019). 
OLSON, H.A. \& D.M. BENSON. 2011. Characterization of Phytophthora spp. on floriculture crops in North Carolina. Plant Dis. 95: 1013-1020

https://doi.org/10.1094/PDIS-09-10-0619

ORIOLANI, E.J.A. \& GATICA, M.E. 1980. Enfermedades causadas por hongos y bacterias en cultivos hortícolas de las provincias de Mendoza y San Juan. Boletín Hortícola 1: 46-47.

PAOLONI, P.J., R. DELHEY \& M. KIEHR. 2002. Enfermedades en cultivos de girasol para producción de semilla híbrida bajo riego, en el Valle Bonaerense del Río Colorado, Argentina. XI Jornadas Fitosanitarias Argentinas. Facultad de Agronomía y Veterinaria. UNRío Cuarto. Córdoba. 26-28 de junio. Libro de Res.: 66.

PALMUCCI, H.E., P.E. GRIJALBA, E. GUILLIN, L. FARÍAS, G. MANTZ \& S. WOLCAN. 2008. Phytophthora cinnamomi, agente causal de podredumbre basal en casuarina. I Congreso Argentino de Fitopatología 28-30 de mayo, Córdoba, Argentina. Libro de Res.: 142.

PALMUCCI, H.E., GRIJALBA, P.E. \& S. WOLCAN. 2011a. Identificación morfológica-molecular de especies de Phytophthora en Argentina. $2^{\circ}$ Congreso Argentino de Fitopatología. Mar del Plata. Buenos Aires. 01-03 de junio. Libro de Resúmenes: 128.

PALMUCCI, H.E., P. GRIJALBA, S. WOLCAN, C. HERRERA, E. FANTINO, M. STECIOW \& G. ABAD. 2011b. Morphological-molecular characterization of Phytophthora, Pythium and Phytopythium on intensive crops in Buenos Aires. Argentina. Phytopathology 101: 136.

PALMUCCI, H.E., P.E. GRIJALBA, E. GUILLIN, S. WOLCAN, M.V. LÓPEZ, C. HERRERA \& E. FANTINO. 2011c. First report of Phytophthora nicotianae affecting Dieffenbachia picta in Argentina. Trop. Plant Pathol. 36: 327-331.

PALMUCCI, H.E., P.E. GRIJALBA \& S. WOLCAN. 2012. Identificación de Phytophthora nicotianae y Pythium sp. nov. afectando Schlumbergera truncata en la provincia de Buenos Aires. XIV Jornadas Fitosanitarias Argentinas, San Luis 3-5 de octubre. Libro de Res.: 33.

PALMUCCI, H.E., S.M. WOLCAN \& P.E. GRIJALBA. 2013. First confirmed report of basal rot of Chamaelucium uncinatum caused by Phytophthora nicotianae in Argentina. Australas. Plant Dis. Notes: 1-3. https://doi.org/10.1007/s13314-013-0090-1

PALMUCCI, H.E. 2015. Caracterización de especies fitopatógenas de Pythium y Phytophthora
(Peronosporomycetes) en cultivos ornamentales de producción intensiva de la provincia de Buenos Aires. Tesis de Doctorado, Facultad de Ciencias Naturales y Museo, UNLP. 447pp.

PELAYO, J.B. 1935. Ficha Fitopatológica Nro. 002300.1 Ficheros y Archivos del Instituto de Patología Vegetal INTA. Archivada en: INTA IMYZA Castelar, Buenos Aires. Solanum tuberosum L. Phytophthora infestans (Mont.) de Bary. En San Carlos de Bariloche, Río Negro. 14/02/1935 (In: http://rian.inta.gov.ar/atlas/\#/Inicio, accessed in November 2018).

PEREDA, F.C. 1955. Ficha Fitopatológica Nro 000513 INTA- IMIZA, Castelar, Buenos Aires. Citrus sinensis L. (Osbeck). Phytophthora syringae. Kleb. Chajarí, Entre Rios, Argentina. 18/01/1955 (In: http://rian.inta.gov.ar/atlas/\#/Inicio, accessed in November 2018).

PEREZ SIERRA, A., B. MORA SALA, M. LEÓN, J. GARCÍA JIMENEZ \& P. ABAD-CAMPOS. 2012. Enfermedades causadas por Phytophthora en viveros de plantas ornamentales. Bol. Sanid. Veg. Plagas 38: 143-156.

PONTIS, R.E. 1941. El mal de la tinta del nogal en la República Argentina. Revista Argent. Agron. 8: 317-325.

PONTIS, R.E. 1945. Phytophthora capsici en frutos de zapallito de tronco. Revista Argent. Agron. 12: 1721.

PONTIS, R.E. \& J.M. FELDMAN. 1958. La podredumbre zonal de los frutos de tomate en Argentina causada por Phytophthora capsici. Revista Argent. Agron. 25: 95-100.

PONTIS, R.E. \& J.M. FELDMAN. 1959. La podredumbre del cuello y las raíces de Callistephus chinensis en la Argentina, causada por Phytophthora cryptogea. Revista Argent. Agron. 26: 17-22.

PONTIS, R.E. \& J.M. FELDMAN. 1960. La podredumbre del cuello del manzano causada por Phytophthora cactorum en la provincia de Mendoza. Sesiones Científicas de Biología. Ciudad de Mendoza. Libro de Res.: 74.

PLOPER, L.D., P. GRIJALBA, M.E. GALLY \& D.E. BARRETO. 1998. Reacción a Phytophthora sojae de variedades y líneas avanzadas de soja adaptadas al noroeste argentino. Avance-Agroindustrial 18: 23-26.

PLOPER, L.D., V. GONZALEZ \& N.V. de RAMALLO. 1999. Presencia de Phytophthora sojae en lotes de soja de Tucumán y Salta. Avance-Agroindustrial 19: 16-19. 


\section{H. E. Palmucci and S. M. Wolcan - The Genus Phytophthora in Argentina}

PRIOLETTA, S.M., C.D. GARCÍA \& M.C. BELLACCOMO. 2006. Identificación de las enfermedades de tomate, papa y pimiento en el valle bonaerense del Río Colorado. XXIX Congreso Argentino de Horticultura. San Fernando del Valle de Catamarca, Argentina, 20-23 de septiembre. Libro de Res.: 69-70.

RAGGI, A. 1945. Ficha Fitopatológica Nro. 000305.2. Ficheros y Archivos del Instituto de Patología Vegetal INTA. Archivada en: INTA IMYZA Castelar, Buenos Aires. Capsicum annuum L., Phytophthora capsici Leonian. En Andalgalá, Catamarca. 12/04/1945 (In: http://rian.inta.gov.ar/ atlas/\#/Inicio, accessed in November 2018).

RIEDER., R. 1887. La enfermedad de la papa. Anales de Santa Catalina (Buenos Aires) 11: 256-258.

RIVERA, M.C., O.S.F. DELFINO, E.R. WRIGHT \& A. RIVERA GONZÁLEZ. 2000. Respuesta de cultivares de Catharanthus roseus frente a Phytophthora parasitica. Hortic. Argent. 19: 52-55.

ROIG, J.M., C.R. GALMARINI \& R.J. PICCOLO. 2009. Identificación de razas de Phytophthora capsici L. en la provincia de Mendoza. XXXII Congreso Argentino de Horticultura. Ciudad de Salta. Salta. 23-26 de septiembre. Libro de Res.: 342.

ROSSINI, M., A. DOBRA \& S. DI MASI. 1992. Phytophthora capsici en hortícolas del Alto Valle de Río Negro y Neuquén. VIII Jornadas Fitosanitarias Argentinas. Paraná. Entre Ríos. 8-11 de septiembre. Libro de Res.: $\mathrm{s} / \mathrm{n}$

ROSSINI, M., A. DOBRA \& S. DI MASI. 1997. Las podredumbres radicales y del cuello en manzanos y perales en Alto Valle de Rio Negro y Neuquén. Rev. Invest. Agropec. (RIA) 28: 73-79.

SÁNCHEZ, A.D., G. CARREÑO, G. LUCERO \& M.C SOSA. 2017. Identificación y caracterización de especies de Phytophthora asociadas al cultivo de peral en Río Negro- Argentina. Cuarto Congreso Argentino de Fitopatología, 19-21 de abril, Mendoza, Argentina, p. 254.

SÁNCHEZ, A.D., M. SOSA, C. LUTZ \& G.S. LUCERO. 2019. Identification and pathogenicity of Phytophthora species in pear commercial orchards in Argentina. Eur. J. Plant Pathol. https://doi.org/10.1007/s10658-019-01705-2

SARASOLA, A.A. \& M.A.R de SARASOLA. 1959. Enfermedades del eucalipto en la Argentina IDIA 139: 1-11.

SCHECHAJ, R. 1954. Evaluación de las variedades de papa según su resistencia a Phytophthora infestans
(Mont.) de Bary, en plantaciones de primaveraverano en la estación experimental "El Suncho", Catamarca. Rev. Agron. Noroeste Arg. 1: 135-155.

SERVICI M.F., G.M. CABARROU, N. PANIEGO, A.F. PUEBLA \& M.F. LUCCA. 2017. Herramientas tecnológicas para el control del tizón tardío de la papa en el sudeste de la Provincia de Buenos Aires. $4^{\circ}$ Congreso Argentino de Fitopatologia. 19 al 21 de abril. Mendoza, Argentina. Libro de Res.: 131

SCHWINGLE, B.W., J. JUZWIK \& B. MOLTZAN. 2007. Phytophthora species in soils associated with declining and nondeclining oaks in Missouri forests. Plant Dis. 91: 633. https://doi.org/10.1094/PDIS-91-5-0633A

SOSA, M.C., M.C. LUTZ, M.L. VÉLEZ \& A. GRESLEBIN. 2015. Pre-harvest rot of pear fruit Golden Russet Bosc caused by Phytophthora lacustris and Phytophthora drechsleri in Argentina. Australas. Plant Dis. Notes 10: 18. https://doi.org/10.1007/s13314-015-0169-y

SPEGAZZINI, C. 1902. Anales Mus. Nac. Buenos Aires 8 (serie $\left.2^{\mathrm{a}}\right): 67$.

STEIN, B.E. \& TORRES LEAL, G.J. 1991. Podredumbre marrón de las frutas cítricas. Avance agroindustrial 12: 23-24 (In: http://rian.inta.gov.ar/atlas/\#/Inicio, accessed in November 2018).

TACCARI L.E., A.G., GRESLEBIN, M.E. SALGADO SALOMÓN \& M.L. VÉLEZ. 2019. Two conifer species native to Patagonia trheatened by Phytophthora austrocedri. For. Pathol. 49 (2) https://doi.org/10.1111/efp.12496

THINES, M. \& Y.J CHOI. 2016. Evolution, Diversity, and Taxonomy of the Peronosporaceae, with Focus on the Genus Peronospora. Phytopathology 106: 6-18. https://doi.org/10.1094/PHYTO-05-15-0127RVW

TRAVERSI, B.A. 1948. Ficha Fitopatológica Nro. 000305.6. Ficheros y Archivos del Instituto de Patología Vegetal INTA. Archivada en: INTA IMYZA Castelar, Buenos Aires. Capsicum annuum L.. Phytophthora capsici Leonian. En San Miguel de Tucumán, Tucumán. 15/04/1948 (In: http://rian. inta.gov.ar/atlas/\#/Inicio, accessed in November 2018).

VAN DAMME, M. \& A. RIDAO. 1994. Determination of races and mating type of Phytophthora infestans isolated in Argentina. Fitopatología 29: 78-82.

VÁZQUEZ de RAMALLO, N.E. 1974. Enfermedades de los paltos. Boletín 116 1-14. Eds. EEA de Tucumán. San Miguel de Tucumán. Tucumán, Argentina, 14pp. 
VÁZQUEZ de RAMALLO, N.E. 1989. Tizón de la hoja del ricino (Ricinus communis L.) causado por Phytophthora parasitica Dastur. Rev. Ind. Agric. Tucumán 66: 135-141.

VECCIETTI, N.B. \& S.R. ZAPATA. 2005. Enfermedades que afectan al cultivo del kenaf en la provincia de Salta, Argentina. XIII Congreso Latinoamericano de Fitopatología. III Taller de la AAF. Libro de Res.: 471

VELASCO, B. \& R.E. PONTIS. 1977. Una podredumbre del cuello y de las raíces de berenjena en la Argentina, causada por Phytophthora capsici. VIII Jornadas y Primer Congreso Argentino de Micología. Libro de Res. 415-419.

VELASCO, B.F. 1981. Microorganismos presentes en semillas de zapallo. IV Jornadas Fitosanitarias Argentinas. Córdoba. 19 - 21 de agosto. Libro de Res.: 20.

VELASCO, B. \& PERINETTI, G. de. 1990. Microorganismos presentes en semillas de melón. XIII Congreso Argentino de Horticultura. Ciudad de Salta. 24-28 de septiembre. Libro de Res.: 42.

VELASCO, B. \& A. CAMARGO. 1994. Espárrago (Asparagus officinalis L.), hongos y bacterias que lo afectan. $7^{\circ}$ Congreso Latinoamericano de Fitopatología, Santiago de Chile. Libro de Res.: 66-67.

VELASCO, B.F., S. DEL TORO, C. LINARDELLI, \& S.R. CASTELLANO. 1997. Estado sanitario de los viveros de olivo en la región del Nuevo Cuyo-Argentina. IX Congreso Latinoamericano de Fitopatología. Montevideo. Uruguay. 12-17 octubre. Libro de Res.: 237.

VÉLEZ, M.L., P.V. SILVA, O.A. TRONCOSO, \& A.G. GRESLEBIN. 2012. Alteration of physiological parameters of Austrocedrus chilensis by the pathogen Phytophthora austrocedrae. Plant Pathol. 61:877-888. https://doi.org/10.1111/j.1365-3059.2011.02585.x

VÉLEZ, M.L., M.P.A. COETZEE, M.J. WINGFIELD, M. RAJCHENBERG \& A.G. GRESLEBIN. 2014. Evidence of low levels of genetic diversity for the Phytophthora austrocedrae population in Patagonia, Argentina. Plant Pathol. 63: 212-220. https://doi.org/10.1111/ppa.12067

VETTRAINO, A.M., G. LUCERO, P. PIZZUOLO, S. FRANCESCHINI \& A. VANNINI. 2009. First report of root rot and twigs wilting of olive trees in Argentina caused by Phytophthora nicotianae. Plant Dis. 93: 765. https://doi.org/10.1094/PDIS-93-7-0765B

VIGLIOLA, M.I. \& CALOT, L. 1982. Hortalizas, enfermedades en poscosecha. Editorial Hemisferio Sur. Buenos Aires.
VIGLIOLA, M.I., L. CALOT \& H. VALLEJO. 1984. Podredumbre en frutilla producida por Phytophthora cactorum. VII Reunión Nacional de SAO. San Pedro. Buenos Aires. Libro de Res.: 108.

VITORIA, E.R. 1941. Ficha Fitopatológica Nro. 000305.1. Ficheros y Archivos del Instituto de Patología Vegetal INTA. Archivada en: INTA IMYZA Castelar, Buenos Aires. Capsicum annuum L.. Phytophthora capsici Leonian. en Santa Rosa, La Pampa, Argentina. 05/03/1941 (In: http://rian.inta. gov.ar/atlas/\#/Inicio, accessed in November 2014).

WARFIELD, C.Y., J. HWANG \& D.M. BENSON. 2008. Phytophthora blight and dieback in North Carolina nurseries during a 2003 survey. Plant Dis. 92: 474481. https://doi.org/10.1094/PDIS-92-3-0474

WATERHOUSE, G.M. 1957. Phytophthora citricola, Sawada, (Syn. Ph. cactorum var. applanata Chester.) Trans. Br. Mycol. Soc. 40: 349-357. https://doi.org/10.1016/S0007-1536(57)80031-X

WHITTAKER, R. H. 1969. New concepts of Kingdoms of organisms. Science 163: 150-160. https://doi. org/10.1126/science.163.3863.150

WOLCAN, S.M. \& LORI, G.A. 2001. Basal rot of geraldton waxplant caused by Phytophthora boehmeriae. Plant Dis. 85: 98. https://doi.org/10.1094/PDIS.2001.85.1.98A

WOLCAN, S.M., P.J. GREGO, A. LÓPEZ, M.C. ROLLÁN, \& A.M. ALIPPI. 2005. Enfermedades que afectan la producción de flor de cera (Chamelaucium uncinatum). VII Jornadas Nacionales de Floricultura. Trevelín, Chubut, Argentina. 19-1 de octubre. Soporte electrónico: CD.

WOLCAN, S.M. \& L.B. RONCO. 2006. Caracterización de cepas de Phytophthora cryptogea aisladas de distintos hospedantes cultivados bajo cobertura. Jornadas de enfermedades en cultivos bajo cubierta. La Plata, Buenos Aires. 29-30 de junio. Libro de Res: 94-95.

WOLCAN, S., L. RONCO \& G. LORI. 2007. Podredumbres basales de Gypsophila paniculada (Caryophylaceae) en la Argentina. Agentes causales y su patogenicidad potencial sobre Dianthus caryophyllus (Caryophylaceae). Bol. Soc. Argent. Bot. 42: 159-167.

YABAR, M.M., P.A. OJEDA, M.J. IRIBARREN, F. POMARES \& M.M STECIOW. 2017. Patogenicidad de Phytophthora capsici obtenida de Coronopus didimus en plantines de mastuerzo. $4^{\circ}$ Congreso argentino de Fitopatología. Ciudad de Mendoza. 19 al 21 de Abril. Libre de Res. 248. 
H. E. Palmucci and S. M. Wolcan - The Genus Phytophthora in Argentina

YAKABE, L.E., C.L. BLOMQUIST, S.L. THOMAS \& J.D. MacDONALD. 2009. Identification and frequency of Phytophthora species associated with foliar diseases in California ornamental nurseries. Plant Dis. 93: 883-890.

https://doi.org/10.1094/PDIS-93-9-0883

YANG, X., B.M. TYLER \& C. HONG. 2017. An expanded phylogeny for the genus Phytophthora. IMA Fungus 82: 355-384.

https://doi.org/10.5598/imafungus.2017.08.02.09

ZENG, H.C., H.H. HO \& F.C. ZHENG. 2009. A survey of Phytophthora species on Hainan Island of South China. J. Fitopatol. 157: 33-39.

https://doi.org/10.1111/j.1439-0434.2008.01441.x 
